Final Author's Version

July 10, 2006

J. Phys. Chem. B

\title{
Aqueous Solvation Free Energies of Ions and Ion-Water Clusters Based on an Accurate Value for the Absolute Aqueous Solvation Free Energy of the Proton
}

\author{
Casey P. Kelly, Christopher J. Cramer*, and Donald G. Truhlar* \\ Department of Chemistry and Supercomputing Institute, 207 Pleasant Street SE, \\ University of Minnesota, Minneapolis, Minnesota 55455-0431 \\ *cramer@chem.umn.edu, truhlar@umn.edu
}

TITLE RUNNING HEAD: Aqueous solvation free energies of ions and ion-water clusters

\begin{abstract}
Thermochemical cycles that involve $\mathrm{p} K_{\mathrm{a}}$, gas-phase acidities, aqueous solvation free energies of neutral species, and gas-phase clustering free energies have been used with the cluster pair approximation to determine the absolute aqueous solvation free energy of the proton. The best value obtained in this work is in good agreement with the value reported by Tissandier et al. (Tissandier, M. D.; Cowen, K. A.; Feng, W. Y.; Gundlach, E.; Cohen, M. J.; Earhart, A. D.; Coe, J. V. J. Phys. Chem. A 1998, 102, 7787), who applied the cluster pair approximation to a less diverse and smaller data set of ions. We agree with previous workers who advocated the value -265.9 $\mathrm{kcal} / \mathrm{mol}$ for the absolute aqueous solvation free energy of the proton. Considering the uncertainties associated with the experimental gas-phase free energies of ions that are required to use the cluster pair approximation as well as analyses of various subsets of
\end{abstract}


data, we estimate an uncertainty for the absolute aqueous solvation free energy of the proton of no less than $2 \mathrm{kcal} / \mathrm{mol}$. Using a value of $-265.9 \mathrm{kcal} / \mathrm{mol}$ for the absolute aqueous solvation free energy of the proton, we expand and update our previous compilation of absolute aqueous solvation free energies; this new data set contains conventional and absolute aqueous solvation free energies for 121 unclustered ions (not including the proton) and 147 conventional and absolute aqueous solvation free energies for 51 clustered ions containing from 1 to 6 water molecules. When tested against the same set of ions that was recently used to develop the SM6 continuum solvation model, SM6 retains its previously determined high accuracy; indeed, in most cases the mean unsigned error improves when it is tested against the more accurate reference data.

\section{Introduction}

Compilations of experimental free energies of solvation are important because they can be used in conjunction with isolated-molecule (gas-phase) data to calculate liquid-phase equilibrium constants and reduction potentials. ${ }^{1-6}$ In addition, they can be used to assess the performance of theoretical methods for condensed-phase simulation. For example, the parameters contained in many continuum solvation models are chosen so as to best reproduce experimental solvation free energies. For neutral species, compilations exist in which solvation free energies have been tabulated for a large number of solutes in aqueous ${ }^{7-14}$ as well as nonaqueous solvents. ${ }^{10,15}$ Because these free energies can be determined directly from experimental partition coefficients, ${ }^{3}$ their uncertainty is typically quite low $(\sim 0.2 \mathrm{kcal} / \mathrm{mol}) .{ }^{16}$ For charged species the situation is quite different. It is generally agreed that the free energy of formation or chemical 
potential of an individual ion "has no operational meaning" $" 17$ in standard thermodynamics because the difference in electric potential between two media cannot be measured and therefore has no physical meaning. ${ }^{18,19}$ Therefore, it is conventional to assign the free energy of one ion, usually the proton, in any medium arbitrarily, and then well-defined sums of free energies for neutral combinations of cations and anions can be converted to single reference values of single-ion free energies. ${ }^{20}$ In statistical thermodynamics, one often calculates single-ion quantities by the same approximate procedures and thermodynamic cycles ${ }^{14,21,22}$ as used for neutral species, and such calculations are very useful for explaining and predicting a large number of experimentally observed or observable phenomena. Therefore, there is great interest in having physically realistic reference values of single-ion free energies to parametrize and validate theoretical models.

Pliego and Riveros reported ${ }^{23}$ absolute aqueous solvation free energies for 56 ions that they determined using $\mathrm{p} K_{\mathrm{a}}$, gas-phase acidities, aqueous solvation free energies of neutral species, and Tissandier et al.'s reference value of $-265.9 \mathrm{kcal} / \mathrm{mol}^{24}$ for the absolute aqueous solvation free energy of the proton. (All numerical values for solvation free energies in this article are reference values for ideal processes in which the concentration is the same in the gas phase and in solution; see section $2 .{ }^{25}$ ) More recently, we reported aqueous solvation free energies for 143 charged species and used these free energies to develop the SM6 continuum solvation model. ${ }^{14}$ For unclustered ions (e.g., $\mathrm{OH}^{-}, \mathrm{CH}_{3} \mathrm{O}^{-}$, etc.), we used the same thermochemical cycles as Pliego and Riveros, although we used Zhan and Dixon's value ${ }^{26}$ of $-264.3 \mathrm{kcal} / \mathrm{mol}$ for the absolute aqueous solvation free energy of the proton instead of Tissandier et al.'s value of $-265.9 \mathrm{kcal} / \mathrm{mol}$. 
As a result, many of the overlapping data points from these two compilations are different from one another by $\sim 1.6 \mathrm{kcal} / \mathrm{mol}$. Pliego and Riveros did not include clustered ions (e.g., $\mathrm{H}_{2} \mathrm{O} \bullet \mathrm{OH}^{-}, \mathrm{H}_{2} \mathrm{O} \bullet \mathrm{CH}_{3} \mathrm{O}^{-}$, etc.) in their work.

Zhan and Dixon's value for the absolute aqueous solvation free energy of the proton has been used in a number of places ${ }^{27}$ to determine absolute aqueous solvation free energies, acid dissociation constants, and redox potentials. Thus, care must be taken when comparing properties obtained based on Tissandier et al.'s and Zhan and Dixon's values (or any other value) for the absolute solvation free energy of the proton. Further complicating the situation is that the wrong standard-state convention has sometimes been associated ${ }^{5,16,28-36}$ with Tissandier et al.'s value, resulting in values that are 1.9 $\mathrm{kcal} / \mathrm{mol}$ less negative than the actual value (and thus close to Zhan and Dixon's value). ${ }^{25}$ Because the differences above are within the previously estimated value ${ }^{14,24,37}$ for the uncertainty associated with the absolute aqueous solvation free energy of the proton, one might argue that Tissandier et al.'s and Zhan and Dixon's values are essentially equivalent. However, as the accuracy of theoretical models for condensed-phase systems increases, the consistency of tabulated data for the aqueous solvation free energies of ions will become an important issue. (For example, a free energy difference of $1.6 \mathrm{kcal} / \mathrm{mol}$ corresponds to 1.2 units in a $K_{\mathrm{a}}$ or $52 \mathrm{mV}$ in a reduction potential at $298 \mathrm{~K}$.) Furthermore, the use of a consistent reference value allows for more meaningful comparisons to be made between data and calculations from different sources.

Like other single ions, the absolute aqueous solvation free energy of the proton cannot be determined directly from experiment, although there has been considerable recent discussion regarding the "best" value for this quantity. ${ }^{24,26,29,37-45}$ Earlier 
compilations of aqueous solvation free energies of ions by Pearson ${ }^{46}$ Florián and Warshel, ${ }^{47}$ and Dolney et al. ${ }^{48}$ used $-261.4 \mathrm{kcal} / \mathrm{mol}$ for the absolute aqueous solvation free energy of the proton, ${ }^{49}$ which is an average of five independent measurements of the standard hydrogen electrode. ${ }^{50-54}$ Tissandier et al. arrived at their value of -265.9 $\mathrm{kcal} / \mathrm{mol}$ using correlations between experimental ion-water clustering data and aqueous solvation free energies of neutral ion pairs. This so-called cluster pair approximation ${ }^{24,37,55}$ has been adopted by several other workers, ${ }^{39,42}$ who were able to reproduce Tissandier et al.'s original result to within $0.7 \mathrm{kcal} / \mathrm{mol}$ using gas-phase singlewater-molecule clustering data. (Tissandier et al. considered clusters containing up to six coordinating water molecules.) Zhan and Dixon's value of $-264.3 \mathrm{kcal} / \mathrm{mol}$, which we used in our previous compilation of aqueous solvation free energies, ${ }^{14}$ was determined using high-level gas-phase calculations coupled with a supermolecule-continuum approach in which specific ion-water interactions were accounted for quantum mechanically using up to 10 explicit water molecules and long-range bulk electrostatic effects were modeled using a dielectric continuum model. However, a potentially serious problem with the solvation free energies reported by Zhan and Dixon is that they are based on a single structure for each number of water molecules.

In a recent communication, Camaioni and Schwerdtfeger ${ }^{43}$ state that Tissandier et al.'s value of $-265.9 \mathrm{kcal} / \mathrm{mol}$ for the absolute aqueous solvation free energy of the proton is the most accurate value for this quantity and that it should not be changed unless/until it is superseded by better measurements. To better understand this, we will apply the cluster pair approximation used by Tissandier et al. to a much larger set of data than has previously been used for this kind of analysis. In this way, we will be able to 
make a better decision as to what value should be used for the absolute aqueous solvation free energy of the proton, thus allowing us to determine accurate absolute aqueous solvation free energies of other single ions. Using these absolute solvation free energies, we will then retest the performance of several continuum solvation models that were tested using less accurate reference data as part of our previous work. ${ }^{14}$

\section{Standard States}

All experimental and calculated gas-phase free energies are tabulated using an ideal gas at $1 \mathrm{~atm}$ as the reference state. Free energies that employ this standard-state definition will be denoted by the superscript degree symbol. In the present article, all experimental and calculated solvation free energies are tabulated for an ideal gas at a gasphase concentration of $1 \mathrm{~mol} / \mathrm{L}$, dissolving as an ideal solution at a liquid-phase concentration of $1 \mathrm{~mol} / \mathrm{L}{ }^{56}$ Free energies that employ this standard state definition will be denoted by a superscript asterisk. The relationship between these two standard states is

$$
G_{\mathrm{g}}^{*}=G_{\mathrm{g}}^{\circ}+\Delta G^{\circ \rightarrow *}
$$

and

$$
\Delta G_{\mathrm{S}}^{*}=\Delta G_{\mathrm{S}}^{\circ}-\Delta G^{\circ \rightarrow *}
$$

where $^{3}$

$$
\Delta G^{\circ \rightarrow *}=R T \ln (24.46)
$$

At $298 \mathrm{~K} \Delta G^{\circ \rightarrow *}$ equals $1.9 \mathrm{kcal} / \mathrm{mol}$. (Thus, for example, if a gas-phase standard state of 1 atm or 1 bar were used instead of a gas-phase standard state of $1 \mathrm{~mol} / \mathrm{L}$, then Tissandier et al.'s solvation free energy of the proton would be $-264.0 \mathrm{kcal} / \mathrm{mol} .^{25}$ ) 


\section{Conventional Aqueous Solvation Free Energies of Ions and Ion-Solvent Clusters}

As reviewed in the Introduction, the absolute solvation free energy of a single ion cannot be measured; instead, solvation free energies of single ions are often tabulated as relative, or conventional free energies by arbitrarily setting the free energy of solvation of the proton equal to zero. This results in a set of conventional free energies of solvation for monovalent cations that are shifted from their absolute values by the unknown value for the solvation free energy of the proton

$$
\Delta G_{\mathrm{S}}^{*, \operatorname{con}}\left(\mathrm{M}^{+}\right)=\Delta G_{\mathrm{S}}^{*}\left(\mathrm{M}^{+}\right)-\Delta G_{\mathrm{S}}^{*}\left(\mathrm{H}^{+}\right)
$$

and conventional free energies of solvation for monovalent anions that are shifted by an equal amount in the opposite direction

$$
\Delta G_{\mathrm{S}}^{*, \operatorname{con}}\left(\mathrm{M}^{-}\right)=\Delta G_{\mathrm{S}}^{*}\left(\mathrm{M}^{-}\right)+\Delta G_{\mathrm{S}}^{*}\left(\mathrm{H}^{+}\right)
$$

(Above, $\mathrm{M}^{+}$refers generically to any monovalent cation, and $\mathrm{M}^{-}$to any monovalent anion. Later in this article, $\mathrm{BH}^{+}$will be used to refer to a cation that behaves as a Brønsted-Lowry acid, and $\mathrm{A}^{-}$will be used to refer to an anion that behaves as a Brønsted-Lowry base. This notation is consistent with that used in two of our earlier

papers. ${ }^{14,57}$ ) When the above convention is used, the following relationship is satisfied

$$
\Delta G_{\mathrm{S}}^{*, \operatorname{con}}\left(\mathrm{M}^{+}\right)+\Delta G_{\mathrm{S}}^{*, \operatorname{con}}\left(\mathrm{M}^{-}\right)=\Delta G_{\mathrm{S}}^{*}\left(\mathrm{M}^{+}\right)+\Delta G_{\mathrm{S}}^{*}\left(\mathrm{M}^{-}\right)
$$

Thus, unlike absolute solvation free energies of single ions, sums of free energies for neutral combinations of cations and anions are well-defined. Through the use of the above relationships, conventional aqueous solvation free energies based on experimental gas and aqueous-phase free energies of formation have been tabulated in various

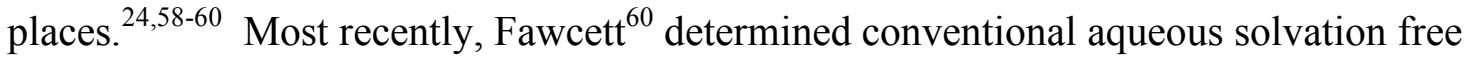


energies for 10 monovalent, monatomic ions (several of the compilations referenced above also contain data for di- and trivalent ions, which will not be considered as part of this work.) The conventional solvation free energies of the monovalent ions reported by Fawcett are listed in Table 1. Also listed in Table 1 are the aqueous solvation free energies reported earlier by Tissandier et al. ${ }^{24}$ (In this reference, there are typographical errors in the values of the conventional solvation free energies of $\mathrm{Cl}^{-}, \mathrm{Br}^{-}$, and $\mathrm{I}^{-}$; these errors have also been pointed out by Coe. ${ }^{55}$ ) The conventional solvation free energies reported by Fawcett and by Tissandier et al. use a standard-state pressure of 1 bar in the gas phase, and a standard-state concentration of $1 \mathrm{~mol} / \mathrm{L}$ in the aqueous phase. To convert these free energies to a standard state that uses a concentration of $1 \mathrm{~mol} / \mathrm{L}$ in both the gas and the aqueous phases, we substituted eq 2 into eqs 4 and 5, which leads to the following relationships between conventional solvation free energies tabulated using these two standard states

$$
\begin{aligned}
& \Delta G_{\mathrm{S}}^{*, \operatorname{con}}\left(\mathrm{M}^{+}\right)=\Delta G_{\mathrm{S}}^{\circ, \operatorname{con}}\left(\mathrm{M}^{+}\right) \\
& \Delta G_{\mathrm{S}}^{*, \mathrm{con}^{-}}\left(\mathrm{M}^{-}\right)=\Delta G_{\mathrm{S}}^{\circ, \mathrm{con}}\left(\mathrm{M}^{-}\right)-2 \Delta G^{\circ \rightarrow *}
\end{aligned}
$$

Additionally, Tissandier et al. define the conventional solvation free energy by setting the aqueous-phase free energy of formation of the proton equal to zero. Using the same value for the free energy of formation of the proton in the gas phase as Tissandier et al. $\left(362.55 \mathrm{kcal} / \mathrm{mol}^{61}\right)$, we converted the solvation free energies tabulated using the convention of Tissandier et al. to solvation free energies tabulated using the convention described above according to

$$
\begin{gathered}
\Delta G_{\mathrm{S}}^{*, \operatorname{con}}\left(\mathrm{M}^{+} ; \text {this work }\right)=\Delta G_{\mathrm{S}}^{*, \operatorname{con}}\left(\mathrm{M}^{+} ; \text {Tissandier et al. }\right)+362.55 \mathrm{kcal} / \mathrm{mol} \\
\Delta G_{\mathrm{S}}^{*, \operatorname{con}}\left(\mathrm{M}^{-} ; \text {this work }\right)=\Delta G_{\mathrm{S}}^{*, \operatorname{con}}\left(\mathrm{M}^{-} ; \text {Tissandier et al. }\right)-362.55 \mathrm{kcal} / \mathrm{mol}
\end{gathered}
$$


Through the use of thermochemical cycle 1 (illustrated in Scheme 1) and eq 1, the absolute aqueous solvation free energy of a cation $\mathrm{BH}+($ where $\mathrm{BH}+/ \mathrm{B}$ is a Brønsted-Lowry acid/base pair) can be written as

$$
\Delta G_{\mathrm{S}}^{*}\left(\mathrm{BH}^{+}\right)=\Delta G_{\mathrm{g}}^{\circ}\left(\mathrm{BH}^{+}\right)+\Delta G^{\circ \rightarrow *}+\Delta G_{\mathrm{S}}^{*}(\mathrm{~B})-\Delta G_{\mathrm{aq}}^{*}\left(\mathrm{BH}^{+}\right)+\Delta G_{\mathrm{S}}^{*}\left(\mathrm{H}^{+}\right)
$$

where $\Delta G_{\mathrm{g}}^{\circ}\left(\mathrm{BH}^{+}\right)$is the gas-phase acidity of $\mathrm{BH}^{+}$, which is equal to

$G^{\circ}(\mathrm{B})+G^{\circ}\left(\mathrm{H}^{+}\right)-G^{\circ}\left(\mathrm{BH}^{+}\right), \Delta G_{\mathrm{S}}^{*}(\mathrm{~B})$ is the aqueous solvation free energy of the neutral species $\mathrm{B}$, and

$$
\Delta G_{\mathrm{aq}}^{*}\left(\mathrm{BH}^{+}\right)=2.303 R T \mathrm{p} K_{\mathrm{a}}\left(\mathrm{BH}^{+}\right)
$$

where $\mathrm{p} K_{\mathrm{a}}$ is the negative common logarithm of the aqueous-phase acid dissociation constant of $\mathrm{BH}^{+}$. Substituting eq 11 into eq 4 and using eq 12 lead to the following expression for the conventional aqueous solvation free energy of $\mathrm{BH}^{+}$

$$
\Delta G_{\mathrm{S}}^{*, \mathrm{con}}\left(\mathrm{BH}^{+}\right)=\Delta G_{\mathrm{g}}^{\circ}\left(\mathrm{BH}^{+}\right)+\Delta G^{\circ \rightarrow *}+\Delta G_{\mathrm{S}}^{*}(\mathrm{~B})-2.303 R T \mathrm{p} K_{\mathrm{a}}\left(\mathrm{BH}^{+}\right)
$$

For an anion $\mathrm{A}^{-}$(where $\mathrm{AH} / \mathrm{A}^{-}$is a Brønsted-Lowry acid/base pair), thermochemical cycle 2 (illustrated in Scheme 2) gives the following expression for the absolute aqueous solvation free energy (where again, eq 1 has been used)

$$
\Delta G_{\mathrm{S}}^{*}\left(\mathrm{~A}^{-}\right)=-\Delta G_{\mathrm{g}}^{\circ}(\mathrm{AH})-\Delta G^{\circ \rightarrow *}+\Delta G_{\mathrm{S}}^{*}(\mathrm{AH})+\Delta G_{\mathrm{aq}}^{*}(\mathrm{AH})-\Delta G_{\mathrm{S}}^{*}\left(\mathrm{H}^{+}\right)
$$

where $\Delta G_{\mathrm{g}}^{\circ}(\mathrm{AH})$ is the gas-phase acidity of $\mathrm{AH}$, which is equal to $G^{\circ}\left(\mathrm{A}^{-}\right)+G^{\circ}\left(\mathrm{H}^{+}\right)-G^{\circ}(\mathrm{AH}), \Delta G_{\mathrm{S}}^{*}(\mathrm{AH})$ is the aqueous solvation free energy of the neutral species $\mathrm{AH}, \Delta G_{\mathrm{S}}^{*}\left(\mathrm{H}^{+}\right)$is the absolute solvation free energy of the proton, and

$$
\Delta G_{\mathrm{aq}}^{*}(\mathrm{AH})=2.303 R T \mathrm{p} K_{\mathrm{a}}(\mathrm{AH})
$$


where $\mathrm{p} K_{\mathrm{a}}$ is the negative common logarithm of the aqueous-phase acid dissociation constant of AH. Substituting eq 14 into eq 5 and using eq 15 lead to the following expression for the conventional aqueous solvation free energy of $\mathrm{A}^{-}$

$$
\Delta G_{\mathrm{S}}^{*, \operatorname{con}}\left(\mathrm{A}^{-}\right)=-\Delta G_{\mathrm{g}}^{\circ}(\mathrm{AH})-\Delta G^{\circ \rightarrow *}+\Delta G_{\mathrm{S}}^{*}(\mathrm{AH})+2.303 R T \mathrm{p} K_{\mathrm{a}}(\mathrm{AH})
$$

Listed in Tables 2 and 3 are the conventional aqueous solvation free energies of anions and cations that were determined using eqs 13 and 16, along with the auxiliary data that were used in these equations. All of the auxiliary data were taken from our previous compilation ${ }^{14}$ except for the $\mathrm{p} K_{\mathrm{a}}$ of acetonitrile. Previously, we used 25 for the $\mathrm{p} K_{\mathrm{a}}$ of acetonitrile, which was obtained by extrapolation of $\mathrm{p} K_{\mathrm{a}}$ data for relatively strong carbon acids. ${ }^{62}$ In this work, we replaced this value by a more accurate value (28.9) that was obtained by a kinetic method. ${ }^{63}$ The value of the conventional aqueous solvation free energy of $\mathrm{OH}^{-}$in Table $3(-370.6 \mathrm{kcal} / \mathrm{mol})$, which was determined using thermochemical cycle 2 and the equations described above, is in nearly perfect agreement with the value reported by Tissandier et al. $(-370.7 \mathrm{kcal} / \mathrm{mol})$, who used the same thermodynamic cycle in their determination of this solvation free energy (see footnote 30 of ref 24).

Conventional solvation free energies of clustered ions can be defined in the same way as unclustered ions, that is

$$
\begin{aligned}
& \Delta G_{\mathrm{S}}^{*, \mathrm{con}}\left[\left(\mathrm{H}_{2} \mathrm{O}\right)_{n} \mathrm{M}^{+}\right]=\Delta G_{\mathrm{S}}^{*}\left[\left(\mathrm{H}_{2} \mathrm{O}\right)_{n} \mathrm{M}^{+}\right]-\Delta G_{\mathrm{S}}^{*}\left(\mathrm{H}^{+}\right) \\
& \Delta G_{\mathrm{S}}^{*, \operatorname{con}}\left[\left(\mathrm{H}_{2} \mathrm{O}\right)_{n} \mathrm{M}^{-}\right]=\Delta G_{\mathrm{S}}^{*}\left[\left(\mathrm{H}_{2} \mathrm{O}\right)_{n} \mathrm{M}^{-}\right]+\Delta G_{\mathrm{S}}^{*}\left(\mathrm{H}^{+}\right)
\end{aligned}
$$

where $n$ is the number of clustering water molecules. Through the use of eq 1 and thermochemical cycle 3 (illustrated in Scheme 3) the conventional solvation free energy 
of clustered cations and anions can be written in terms of the conventional solvation free energy of their analogous unclustered ions according to

$$
\Delta G_{\mathrm{S}}^{*, \operatorname{con}}\left[\left(\mathrm{H}_{2} \mathrm{O}\right)_{n} \mathrm{M}^{ \pm}\right]=\Delta G_{\mathrm{S}}^{*, \operatorname{con}}\left(\mathrm{M}^{ \pm}\right)-\Delta G_{[n]}^{\circ}\left(\mathrm{M}^{ \pm}\right)+n \Delta G_{\mathrm{S}}^{*}\left(\mathrm{H}_{2} \mathrm{O}\right)+n \Delta G^{\circ \rightarrow *}
$$

where $\Delta G_{\mathrm{S}}^{*}\left(\mathrm{H}_{2} \mathrm{O}\right)$ is the aqueous solvation free energy of water and $\Delta G_{[n]}^{\circ}\left(\mathrm{M}^{ \pm}\right)$is the sum of the stepwise clustering free energies of $\mathrm{M}^{ \pm}$with $n \mathrm{H}_{2} \mathrm{O}$ molecules in the gasphase

$$
\Delta G_{[n]}^{\circ}\left(\mathrm{M}^{ \pm}\right)=\sum_{i=1}^{n} \Delta G_{i-1, i}^{\circ}\left(\mathrm{M}^{ \pm}\right)
$$

In the above equation, $\Delta G_{i-1, i}^{\circ}=G^{\circ}\left[\left(\mathrm{H}_{2} \mathrm{O}\right)_{i} \mathrm{M}^{ \pm}\right]-G^{\circ}\left[\left(\mathrm{H}_{2} \mathrm{O}\right)_{i-1} \mathrm{M}^{ \pm}\right]-G^{\circ}\left(\mathrm{H}_{2} \mathrm{O}\right)$. Note that the concentration of water $(55.6 \mathrm{~mol} / \mathrm{L}$ at $298 \mathrm{~K})$ does not appear in eq 19 because we use as a standard state an ideal dilute solution, for which the activity of water is very nearly equal to unity. ${ }^{64}$ In this standard-state convention (which we have also used in previous work ${ }^{14,57}$ ), the free energy associated with the following reaction (i.e., the bottom leg of thermochemical cycle 3)

$$
\mathrm{M}^{ \pm}(\mathrm{aq})+n \mathrm{H}_{2} \mathrm{O}(\mathrm{l}) \rightarrow\left(\mathrm{H}_{2} \mathrm{O}\right)_{n} \mathrm{M}^{ \pm}(\mathrm{aq})
$$

is equal to zero for any value of $n .^{65}$

The aqueous solvation free energy of water is known experimentally from the vapor pressure of the pure liquid; ${ }^{43}$ thus, once the conventional aqueous solvation free energy of the unclustered ion is known, the only remaining quantities needed to determine the conventional solvation free energy of a the analogous ion-water cluster are the stepwise gas-phase clustering free energies (e.g., to determine the conventional aqueous solvation free energy for a cluster ion containing four water molecules, the free 
energy changes associated with attaching a single water molecule to the bare ion and the singly, doubly, and triply clustered ion are required). In our previous compilation of aqueous solvation free energies, ${ }^{14}$ we reported experimental and calculated gas-phase clustering free energies for 31 ion-water clusters containing a single water molecule. As part of this work, we updated some of our previous cluster data and expanded the data set with respect to both the number of ions and the number of clustering water molecules considered.

In our previous compilation of gas-phase clustering free energies, we incorrectly used a value of $-12.5 \mathrm{kcal} / \mathrm{mol}$ for $\Delta G_{0,1}^{\circ}\left(\mathrm{F}^{-}\right)$. In this work this value has been replaced by a value of $-21.9 \mathrm{kcal} / \mathrm{mol}$, which was taken from the National Institute of Standards and Technology (NIST) tables ${ }^{66}$ and was determined by extrapolating to $298 \mathrm{~K}$ equilibrium gas-phase data for $\left(\mathrm{H}_{2} \mathrm{O}\right) \mathrm{F}^{-}$measured between 630 and $800 \mathrm{~K}^{67}$ We also updated the value for $\Delta G_{0,1}^{\circ}\left(\mathrm{H}_{3} \mathrm{O}^{+}\right)$, for which we previously used a calculated $\left(\mathrm{B} 97-1^{68} /{\mathrm{MG} 3 \mathrm{~S}^{69}}\right.$ level of theory) value of $-27.0 \mathrm{kcal} / \mathrm{mol}$. This value has been replaced by a value of $-24.5 \mathrm{kcal} / \mathrm{mol}$, which is the average of two independent experimental determinations of this quantity. ${ }^{70,71}$ Making the two changes described above and adding new experimental gas-phase clustering data results in a data set of 132 experimental clustering free energies for 36 ion-water clusters containing, in some cases, up to 6 clustering water molecules plus 15 calculated (B97-1/MG3S) clustering free energies for ion-water clusters containing a single water molecule. This data set, along with references for the experimental data, is given in Tables 4 and 6 (the final column of Table 6 is described below). 
Using eqs 17-20, along with the conventional aqueous solvation free energies in Tables 1-3 (in Table 1, we used the data of Fawcett) and the experimental gas-phase clustering free energies in Table 4, we determined conventional aqueous solvation free energies for all of the ion-water clusters in Table 4. These conventional aqueous solvation free energies are given in Table 5. We also determined conventional aqueous solvation free energies for all of the ion-water clusters listed in Table 6 using the calculated gas-phase clustering data reported in this same table. These conventional aqueous solvation free energies are listed in the final column of Table 6.

\section{Cluster Pair Approximation for Determining Absolute Single Ion Solvation Free}

\section{Energies}

The cluster pair approximation described by Tissandier et al. ${ }^{24}$ is based on the approximation that the difference between the absolute solvation free energy of a positive and negative cluster ion goes to zero as the cluster size becomes infinite, that is ${ }^{72,73}$

$$
\lim _{n \rightarrow \infty}\left\{\Delta G_{\mathrm{S}}^{*}\left[\left(\mathrm{H}_{2} \mathrm{O}\right)_{n} \mathrm{M}^{-}\right]-\Delta G_{\mathrm{S}}^{*}\left[\left(\mathrm{H}_{2} \mathrm{O}\right)_{n} \mathrm{M}^{+}\right]\right\}=0
$$

Subtracting eq 17 from eq 18 and dividing the result by 2 gives

$$
\begin{aligned}
\frac{1}{2}\left\{\Delta G_{\mathrm{S}}^{*, \operatorname{con}_{2}}\left[\left(\mathrm{H}_{2} \mathrm{O}\right)_{n} \mathrm{M}^{-}\right]-\Delta G_{\mathrm{S}}^{*, \operatorname{con}}\left[\left(\mathrm{H}_{2} \mathrm{O}\right)_{n} \mathrm{M}^{+}\right]\right\}= \\
\qquad \frac{1}{2}\left\{\Delta G_{\mathrm{S}}^{*}\left[\left(\mathrm{H}_{2} \mathrm{O}\right)_{n} \mathrm{M}^{-}\right]-\Delta G_{\mathrm{S}}^{*}\left[\left(\mathrm{H}_{2} \mathrm{O}\right)_{n} \mathrm{M}^{+}\right]\right\}+\Delta G_{\mathrm{S}}^{*}\left(\mathrm{H}^{+}\right)
\end{aligned}
$$

Substituting this result into eq 22 gives

$$
\frac{1}{2} \lim _{n \rightarrow \infty}\left\{\Delta G_{\mathrm{S}}^{*, \operatorname{con}}\left[\left(\mathrm{H}_{2} \mathrm{O}\right)_{n} \mathrm{M}^{-}\right]-\Delta G_{\mathrm{S}}^{*, \mathrm{con}}\left[\left(\mathrm{H}_{2} \mathrm{O}\right)_{n} \mathrm{M}^{+}\right]\right\}=\Delta G_{\mathrm{S}}^{*}\left(\mathrm{H}^{+}\right)
$$

Substituting eq 19 into the left-hand side (lhs) of eq 24 leads to 
$\frac{1}{2}\left[\Delta G_{\mathrm{S}}^{*, \operatorname{con}}\left(\mathrm{M}^{-}\right)-\Delta G_{\mathrm{S}}^{*, \operatorname{con}}\left(\mathrm{M}^{+}\right)+\Delta G_{[\infty]}^{\circ}\left(\mathrm{M}^{+}\right)-\Delta G_{[\infty]}^{\circ}\left(\mathrm{M}^{-}\right)\right]=\Delta G_{\mathrm{S}}^{*}\left(\mathrm{H}^{+}\right)$

Separation of the lhs of the above equation into a part for which cluster data are known up to $n$ and a part for which cluster data are not known $(n+1$ to $\infty)$ leads to the following equation

$$
\begin{aligned}
\frac{1}{2}\left[\Delta G_{\mathrm{S}}^{*, \mathrm{con}}\left(\mathrm{M}^{-}\right)-\Delta G_{\mathrm{S}}^{*, \mathrm{con}}\left(\mathrm{M}^{+}\right)+\Delta G_{[n]}^{\circ}\left(\mathrm{M}^{+}\right)-\Delta G_{[n]}^{\circ}\left(\mathrm{M}^{-}\right)\right] & = \\
& \frac{1}{2}\left[\Delta G_{[n+1, \infty]}^{\circ}\left(\mathrm{M}^{-}\right)-\Delta G_{[n+1, \infty]}^{\circ}\left(\mathrm{M}^{+}\right)\right]+\Delta G_{\mathrm{S}}^{*}\left(\mathrm{H}^{+}\right)
\end{aligned}
$$

where the unknown part has been moved to the right-hand side (rhs). The lhs of the above equation is an approximation to the proton's aqueous solvation free energy, based on differential solvation free energies for given cation-anion pairs. These free energy differences can be determined using available experimental or high-level theoretical data in thermochemical cycles 1 and 2. Both of the terms on the rhs are unknown. Thus, the goal of the cluster pair approximation (eq 26) is to identify a cation-anion pair for which the first term on the rhs of eq 26 equals zero, in which case the lhs of eq 26 is equal to the proton's true aqueous solvation free energy. (This anion-cation pair need not actually exist.) Tissandier et al. have shown ${ }^{24}$ that an effective way to do this is by plotting the lhs of eq 26 against half the difference between the conventional solvation free energy of $\mathrm{M}^{-}$ and $\mathrm{M}^{+}$for different values of $n$, giving $n$ straight lines that share a common intersection point at the true value for the aqueous solvation free energy of the proton. 


\section{Absolute Aqueous Solvation Free Energy of the Proton Obtained Using the}

\section{Cluster Pair Approximation}

Shown in Figure 1 is a plot of half the difference between conventional aqueous solvation free energies of anions and of cations for cluster ions containing up to six water molecules against half the difference between conventional aqueous solvation free energies of anions and of cations containing no water molecules, for different numbers of clustering water molecules. The differential conventional aqueous solvation free energies in this plot were computed using all of the conventional aqueous solvation free energies in Tables 5 and 6 (a total of 1109 data points). The straight lines in this plot are best-fit lines for different numbers of clustering water molecules. The line for $n=0$ (no clustering water molecules) is the ideal line $(y=x)$. The ordinate of the intersection point between each line gives an approximate value for the absolute aqueous solvation free energy of the proton, so in all, 21 individual determinations of the absolute aqueous solvation free energy of the proton can be made from the data shown in Figure 1 (The 7 straight lines give 21 unique intersection points between different values of $n$.) To determine the best value of the absolute aqueous solvation free energy of the proton, we used the same method of statistical analysis as Tuttle et al. ${ }^{39}$ For this, the average intersection ordinate of the $i$ th straight line with all others $\left(Y_{i}\right)$ is given by

$$
Y_{i}=\frac{1}{6} \sum_{j \neq i=0}^{6} y_{i j}
$$

where

$$
y_{i j}=\left(m_{i} b_{j}-m_{j} b_{i}\right) /\left(m_{i}-m_{j}\right)
$$


In the above equation, $y_{i j}$ is the ordinate of the intersection point between the $i$ th and $j$ th straight line, and $m_{i}$ and $b_{i}$ are the slope and intercept, respectively, of the $i$ th straight line. In this work, we take the best value for the absolute aqueous solvation free energy of the proton to equal the average of the six $Y_{i}$ values determined using eqs 27 and 28 . For the data shown in Figure 1, this average equals $-266.1 \mathrm{kcal} / \mathrm{mol}$, which is in excellent agreement with the value of $-265.9 \mathrm{kcal} / \mathrm{mol}$ obtained by Tissandier et al. ${ }^{24}$ The standard deviation of the 21 values of $y_{i j}$ from the average value of $y_{i j}$ is $0.71 \mathrm{kcal} / \mathrm{mol}$. The individual slopes, intercepts, and $Y_{i}$ and $y_{i j}$ values obtained from the data shown in Figure 1 as well as the other data subsets described below are included as Supporting Information.

We also applied eqs 27 and 28 to the slopes and intercepts obtained using the conventional aqueous solvation free energies and gas-phase clustering free energies reported by Tissandier et al. (four cation-ion water clusters and five anion-water clusters, containing up to six clustering water molecules; total of 109 data points). Doing this yields a value of $-265.6 \mathrm{kcal} / \mathrm{mol}$ for the absolute aqueous solvation free energy of the proton, which is again in excellent agreement with the original value reported by Tissandier et al. (who used a different method of statistical analysis, and did not consider the $n=0$ line in their fits). The standard deviation of the 21 values of $y_{i j}$ determined using the above subset of data from the average value of $y_{i j}$ is $0.71 \mathrm{kcal} / \mathrm{mol}$. The results of the two fits described above are summarized in Table 7. (Other data in this table are described below.)

Tissandier et al. have pointed out that a useful feature of the cluster pair approximation is that the results do not become intrinsically more accurate as the number 
of clustering water molecules $(n)$ is increased. Thus, the simplest application of the cluster pair approximation is to plot the lhs of eq 26 versus the rhs for $n=1$. (In this case, the absolute aqueous solvation free energy of the proton is given by the intersection of the lines for $n=0$ and $n=1$.) The accuracy of the cluster pair approximation in cases where only a small number of gas-phase clustering data are used has been demonstrated by Tuttle et al. ${ }^{39}$ and Bartels et al. ${ }^{42}$ Applying the cluster pair approximation to clustered ions containing only a single water molecule, and using the same values for the conventional solvation free energies and gas-phase binding free energies as Tissandier et al., Tuttle et al. ${ }^{39}$ obtained a value of $-265.2 \mathrm{kcal} / \mathrm{mol}$ for the absolute aqueous solvation free energy of the proton, which is in good agreement with Tissandier et al.'s value of $-265.9 \mathrm{kcal} / \mathrm{mol}$ obtained using clustered ions containing up to six water molecules. As part of this work, we repeated the analysis of Tuttle et al. and obtained a value of -265.1 $\mathrm{kcal} / \mathrm{mol}$. More recently, Bartels et al. ${ }^{42}$ applied the cluster-pair approximation to clustered ions containing a single water molecule for 6 of the 10 ions that Tissandier et al. used. These workers obtained a value of $-265.8 \mathrm{kcal} / \mathrm{mol}$.

However, for our full set of unclustered and singly clustered ions, the ordinate of the intersection of the $n=0$ and $n=1$ lines (the two solid black lines in Figure 1) is $-268.4 \mathrm{kcal} / \mathrm{mol}$, which is significantly more negative than any of the values described above. It is worth noting that the ordinate of the intersection between the $n=0$ and $n=1$ lines is the one most prone to error because small changes in the slope of the $n=1$ line (which has the largest slope of the $n \geq 1$ lines) will cause the correspondingly largest variation in the value of the ordinate at its intersection point with the ideal line. To better understand the issues associated with singly clustered ions, we performed some 
additional analyses based on various subsets of data; the results of these analyses are described below.

One possible explanation for the quantitative variation described above is that there are many anions and cations for which gas-phase clustering free energies are available only for clustered ions containing a single water molecule (i.e., these anions and cations do not contribute to the slopes and intercepts of the $n \geq 2$ lines), and these species may be unusual in some respect. To test this hypothesis, we removed all of the conventional aqueous solvation free energies for these ions. Thus, all of the conventional aqueous solvation free energies in Table 6 were removed, plus conventional aqueous solvation free energies for 5 of the anions and for 6 of the cations in Table 5. Removing these conventional aqueous solvation free energies decreases the total number of differences between conventional aqueous solvation free energies of clustered anions and of clustered cations containing a single water molecule from 637 to 150 . This subset of differential aqueous solvation free energies gives a value of $-266.6 \mathrm{kcal} / \mathrm{mol}$ for the absolute aqueous solvation free energy of the proton, which is indeed in better agreement with the value reported by Tissandier et al. than when the conventional aqueous solvation free energies of all of the clustered anions and of the clustered cations containing a single water molecule were used.

Besides the number of clustering water molecules considered, we also found that the results are sensitive to whether data for certain types of cations are included in the fits. In particular, we found that the value of the absolute aqueous solvation free energy of the proton obtained using differences between conventional aqueous solvation free energies of anions and of monatomic cations (e.g., alkali metal ions) is significantly 
different than that obtained using differences between conventional aqueous solvation free energies of anions and of oxonium cations. Similarly, the value of the absolute aqueous solvation free energy of the proton obtained using differences between conventional aqueous solvation free energies of anions and of ammonium cations is significantly different than that obtained using either of the two subsets described above. To demonstrate this in a quantitative way, we divided the differences between conventional aqueous solvation free energies of anions and of cations that are shown in Figure 1 (1109 differential solvation free energies) into three different subsets: the monatomic cation subset, which includes only those differences between conventional aqueous solvation free energies of anions and of monatomic cations (377 differential conventional aqueous solvation free energies); the oxonium ion subset, which includes only those differences between conventional aqueous solvation free energies of anions and of oxonium ions (334 differential conventional aqueous free energies); and the ammonium ion subset, which includes only those differences between conventional aqueous solvation free energies of anions and of ammonium ions (398 differential conventional aqueous free energies). Both the monatomic cation subset and the oxonium ion subset contain differences between conventional aqueous solvation free energies of clustered anions and of clustered cations containing up to six water molecules; the ammonium ion subset contains differences between conventional aqueous solvation free energies of clustered anions and of clustered cations containing up to five water molecules. When eqs 27 and 28 are applied to the slopes and intercepts obtained using each of the three subsets described above, the resulting values for the absolute aqueous solvation free energy of the proton are $-265.1,-267.8$, and $-265.8 \mathrm{kcal} / \mathrm{mol}$ for the 
monatomic cation, oxonium ion, and ammonium ion subsets, respectively. This trend is illustrated graphically in Figure 2, which is the same as the plot shown in Figure 1, except that in Figure 2 only the $n=1$ line is shown, and the data points from the monatomic cation, oxonium ion, and ammonium ion subsets are shown in black, red, and blue, respectively. (Analogous plots for $n=2-6$ are not shown here, although the trends are the same as those for $n=1$.)

The result from the analysis presented in the preceding paragraph suggests that the good agreement between the value reported by Tissandier et al. and the value obtained here using all of the data in Tables 5 and $6(-266.2 \mathrm{kcal} / \mathrm{mol})$ is somewhat fortuitous, because it relies on a cancellation of errors (with respect to the value reported by Tissandier et al.) between the three subsets of data described above. The above result also helps to explain why the agreement between the value reported by Tissandier et al. and the value obtained here using clustered ions containing a single water molecule improved significantly when conventional aqueous solvation free energies of anions and of cations for which only gas-phase clustering free energies of clustered ions containing a single water molecule are available were removed. For clustered ions containing a single water molecule, there are 174, 203, and 260 differences between conventional aqueous solvation free energies of anions and of monatomic cations, of oxonium ions, and of ammonium ions, respectively. Thus, the relative ratio of the number of differential solvation free energies belonging to these three subsets of data is approximately 1:1.2 :1.5. The weighted average of the three values for the absolute solvation free energy of the proton obtained using each of these three subsets of data $(-264.4,-271.3$, and -267.7 $\mathrm{kcal} / \mathrm{mol}$ ) is $-267.9 \mathrm{kcal} / \mathrm{mol}$. After removal of the conventional aqueous solvation free 
energies of anions and of cations for which only gas-phase clustering free energies of clustered ions containing a single water molecule are available, there remain 60,40 , and 50 differential conventional aqueous solvation free energies in the monatomic cation, oxonium ion, and ammonium ion subsets, respectively. This changes the relative ratio of the number of differential solvation free energies belonging to these three subsets of data to approximately 1.5:1:1.2. The weighted average of the three values for the absolute solvation free energy of the proton obtained using each of these three subsets of data $(-263.7,-269.3$, and $-266.8 \mathrm{kcal} / \mathrm{mol})$ is $-266.2 \mathrm{kcal} / \mathrm{mol}$, which is $1.7 \mathrm{kcal} / \mathrm{mol}$ more positive than the weighted average from above.

This change in the relative ratio of monatomic cations, oxonium ions, and ammonium ions included in this fit can also be used to explain why the ordinate of the intersection between the $n=0$ and $n=1$ plot is significantly more negative than the ordinate of the intersections between all of the other lines. The relative ratio of the number of differences between conventional aqueous solvation free energies of clustered anions and of clustered monatomic cations, oxonium ions, and ammonium ions, for clusters containing two water molecules, is approximately 1.5:1:1.3, which is different than the relative ratio between these three subsets of data for $n=1$, which is 1:1.2:1.5. For $n=3$, the relative ratio between these three subsets of data is identical to that for $n=$ 2; the relative ratios for $n=4,5$, and 6 are similar to that for $n=2$ and $n=3$. Thus, the poor agreement between the value reported by Tissandier et al. and the value obtained in this work using only clustered ions containing a single water is due to variations in the number of data from the three subsets of data described above, each of which gives a significantly different value for the absolute aqueous solvation free energy of the proton. 
For many of the ions above, we used theoretical values for the gas-phase clustering free energies because experimental data are not available. Of the 29 gas-phase clustering free energies for clustered anions containing a single water molecule, 14 of these were calculated at the B97-1/MG3S level of theory. (The current data set does not contain any calculated data for $n>1$.) This level of theory was used here, and in previous work ${ }^{14,57}$ because it has been shown ${ }^{74-77}$ to perform well for nonbonded interactions in the gas phase. The gas-phase clustering free energy of $\left(\mathrm{H}_{2} \mathrm{O}\right)\left(\mathrm{C}_{2} \mathrm{H}_{5}\right)_{2} \mathrm{OH}^{+}$ was calculated at the same level of theory as above. Thus, of the 1109 differential conventional aqueous solvation free energies in the full data set, 322 were determined using at least one calculated value for the gas-phase clustering free energy (all of these for $n=1$ ). Because many of the data points appearing in Figure 1 were determined using theoretical gas-phase clustering free energies, an obvious question is, what effect does inclusion of theoretical data have on the value obtained for the absolute solvation free energy of the proton? To answer this question, we removed all of the theoretical gasphase data, and applied eqs 27 and 28 to the slopes and intercepts obtained using the remaining data. Doing this leads to an absolute aqueous solvation free energy of the proton of $-266.1 \mathrm{kcal} / \mathrm{mol}$, with a standard deviation of $y_{i j}$ from the average value of $y_{i j}$ equal to $0.70 \mathrm{kcal} / \mathrm{mol}$. The ordinate of the intersection of the lines for $n=0$ and $n=1$ is $-268.0 \mathrm{kcal} / \mathrm{mol}$. All of these values are nearly identical to those obtained with the full data set, demonstrating that the B97-1/MG3S level of theory is able to predict gas-phase clustering free energies of clustered ions (in particular, clustered anions) containing a single water molecule to very high accuracy. 
The results from several recent bulk liquid simulations suggest a value for the absolute solvation free energy of the proton that is close to $-252 \mathrm{kcal} / \mathrm{mol},{ }^{40,41,78,79}$ which is nearly $14 \mathrm{kcal} / \mathrm{mol}$ more positive than the value reported by Tissandier et al. Some recent discussion has focused on the electrical potential of the bulk water interface and its relationship to the absolute solvation free energies of single ions..$^{40,41,44,45}$ In particular, Asthagiri and co-workers ${ }^{40}$ have argued that, for a single ion, the intrinsic solvation free energy, which differs from the absolute solvation free energy by the free energy associated with moving the ion through the electrical potential at the air-liquid interface, is a more realistic measure of the solvation free energy because it does not include the contribution due to the potential of the phase, which is independent of solute-solvent interactions. Indeed, the above separation of the solvation free energy into an intrinsic and an electrical part has been applied for some time to single ions, ${ }^{80-83}$ and it recently has been shown ${ }^{45}$ that when the value for the solvation free energy of the proton obtained from the above simulations is corrected using a theoretical value ${ }^{84}$ for the electrical potential at the air-water interface, the corrected value and the value reported by Tissandier et al. are in relatively good agreement with one another. (Obtaining an accurate value for the electrical potential at the air-water interface has been the subject of much work, and most theoretical attempts at calculating this value predict a potential that differs in both magnitude and sign from the best experimental estimates. ${ }^{85}$ ) In this article, no attempt has been made to separate any of the solvation free energies obtained using the cluster pair approximation or any of the calculated solvation free energies obtained using the continuum solvation models described in the following sections. Nevertheless, one should be aware that the above separation of the absolute solvation free energies of 
single ions has sometimes been employed, and care should be taken when comparing solvation free energies of single ions obtained from different sources.

On the basis of the results presented above, we can make several conclusions regarding the value for the absolute aqueous solvation free energy of the proton. First, the most accurate value obtained for this quantity in this work is $-266.1 \mathrm{kcal} / \mathrm{mol}$, which was determined using all of the conventional solvation free energies listed in Tables 5 and 6. This value is in excellent agreement with the value obtained by Tissandier et al., who used a much smaller data set of conventional aqueous solvation free energies. Thus, we agree with Camaioni and Schwerdtfeger ${ }^{43}$ and suggest using a value of -265.9 $\mathrm{kcal} / \mathrm{mol}$ for the absolute aqueous solvation free energy of the proton in all future applications. We note that this choice also determines the absolute potential of the normal hydrogen electrode (NHE) as $4.28 \mathrm{~V}$. (See ref 5; this value differs from the 4.36 $\mathrm{V}$ value derived in that reference because of the incorrect addition there of $\Delta G^{\circ \rightarrow *}$ to the Tissandier proton solvation free energy of $-264.0 \mathrm{kcal} / \mathrm{mol}$ that already includes the free energy associated with the standard-state change. ${ }^{25}$ ) Second, including theoretical gasphase clustering data has little effect on the value obtained for the absolute aqueous solvation free energy of the proton, suggesting that augmenting experimental gas-phase clustering free energies with theoretical ones could be used in applications of the cluster pair approximation to media for which few experimental gas-phase clustering data exist. Third, the value obtained here for the absolute aqueous solvation free energy of the proton is sensitive to the types of cations used to determine this value. In previous studies that used the cluster pair approximation, the data sets were limited to mainly monatomic ions. By augmentation of the data used in these previous studies with data for 
polyatomic ions, inconsistencies in the value obtained for the absolute aqueous solvation free energy of the proton obtained using different subsets of the cationic data have been revealed. In particular, by analyzing subsets of data containing differences between conventional aqueous solvation free energies of anions and of either monatomic cations, oxonium cations or ammonium ions, we demonstrated how the cluster pair approximation is sensitive to variations in the data set.

In previous work, we have used $3 \mathrm{kcal} / \mathrm{mol}$ as an estimate of the uncertainty associated with the absolute aqueous solvation free energy of a typical ion. ${ }^{14}$ Tissandier et al. report an uncertainty of $2 \mathrm{kcal} / \mathrm{mol}$ for the absolute aqueous solvation free energy of the proton (see the footnote in Table 6 of ref 24), based on the uncertainties associated with the conventional aqueous solvation free energies and gas-phase clustering free energies used in their work. Tissandier et al. also noted that their cluster pair analysis gave a value of $0.07 \mathrm{kcal} / \mathrm{mol}$ as the standard deviation of the average intersection ordinate of each line with all the others from the mean ( $Y_{i}$ in eq 27). In Table 7, we report values for the standard deviation of the ordinate of the intersection point between our lines with all others $\left(y_{i j}\right.$ in eq 28) for each of our fits. (For those fits where $n=1$, there is only one $y_{i j}$ value, so the standard deviation is undefined.) The values reported for the standard deviation in Table 7 range from 0.65 to $1.15 \mathrm{kcal} / \mathrm{mol}$, depending on the data set used. While these standard deviations are useful for assessing the quality of the different fits reported by Tissandier et al. and in this article, we do not believe that any of these standard deviations should be equated to the uncertainty associated with the absolute aqueous solvation free energy of the proton. This is because the standard deviation (as defined here or in ref 24) does not take into account the uncertainty 
associated with the gas-phase binding free energies, which for most of the ions considered in this work are around $2 \mathrm{kcal} / \mathrm{mol}$. Additionally, for those conventional aqueous solvation free energies determined using thermochemical cycles 1 and 2, the experimental values used for the gas-phase acidities have associated with them an

uncertainty between 1 and $2 \mathrm{kcal} / \mathrm{mol} .^{14,86}$ Finally, it was shown above that depending on the cationic data used the value for the absolute aqueous solvation free energy of the proton can fluctuate by up to $7.6 \mathrm{kcal} / \mathrm{mol}$. On the basis of these results, we suggest that an uncertainty of no less than $2 \mathrm{kcal} / \mathrm{mol}$ should be assigned to the absolute aqueous solvation free energy of the proton.

\section{Absolute Aqueous Solvation Free Energies of Single Ions and Ion-Water Clusters Based on Tissandier et al.'s Value for the Absolute Aqueous Solvation Free Energy of the Proton}

Through the use of Tissandier et al.'s value for the absolute aqueous solvation free energy of the proton $(-265.9 \mathrm{kcal} / \mathrm{mol})$, all of the conventional aqueous solvation free energies in Tables 1-3 and in Tables 5 and 6 were converted to absolute aqueous solvation free energies using eqs $4,5,17$, and 18 . The absolute aqueous solvation free energies of the unclustered ions are given in Table 8; those for clustered ions (containing up to six clustering water molecules) are given in Table 9. Also given in Tables 8 and 9 are the absolute aqueous solvation free energies from our earlier compilation, as well as those reported by Pliego and Riveros, ${ }^{23}$ when available.

The data set presented in this article contains a significantly larger number of absolute aqueous solvation free energies than either of the two previous compilations, in 
particular for clustered ions. Our earlier data set of ions contains absolute aqueous solvation free energies for 112 unclustered ions (not including $\mathrm{H}^{+}$), and 31 clustered ions containing a single water molecule. The current data set, which is both an update and expansion of our earlier data set, contains absolute aqueous solvation free energies for 121 unclustered ions (not including $\mathrm{H}^{+}$), and 147 absolute aqueous solvation free energies for 51 clustered ions containing in some cases up to 6 water molecules.

Besides the number of ions and number of clustering water molecules considered, the current data set differs from our earlier data set by the value used for the absolute aqueous solvation free energy of the proton. Our earlier compilation used a value of $-264.3 \mathrm{kcal} / \mathrm{mol}$ for this quantity; thus, the absolute aqueous solvation free energies reported here differ from those listed in our previous compilation by $+1.6 \mathrm{kcal} / \mathrm{mol}$ for anions and $-1.6 \mathrm{kcal} / \mathrm{mol}$ for cations. For $\mathrm{CH}_{2} \mathrm{CN}^{-}$, an additional difference of -5.3 $\mathrm{kcal} / \mathrm{mol}$ is due to an update in the experimental $\mathrm{p} K_{\mathrm{a}}$ of acetonitrile from 25 to 28.9 , as described above. For $\left(\mathrm{H}_{2} \mathrm{O}\right) \mathrm{F}^{-}$, an additional difference of $-7.5 \mathrm{kcal} / \mathrm{mol}$ (which is partially canceled by the $+1.6 \mathrm{kcal} / \mathrm{mol}$ difference from above) is due to the use of an incorrect value for the experimental gas-phase clustering free energy of $\mathrm{F}^{-}$in our previous compilation (also described above). Finally, for $\left(\mathrm{H}_{2} \mathrm{O}\right) \mathrm{H}_{3} \mathrm{O}^{+}$, an additional difference of $-2.5 \mathrm{kcal} / \mathrm{mol}$ is due to an update in the value used for the gas-phase clustering free energy. The largest discrepancy between any of the solvation free energies reported here and by Pliego and Riveros ${ }^{23}$ is $\mathrm{CN}^{-}$, for which the current work gives a value $2.5 \mathrm{kcal} / \mathrm{mol}$ more negative than Pliego and Riveros' value. Inspection of the experimental data used in each of these compilations reveals that a difference in the 
experimental value for the gas-phase acidity of HCN is responsible for this discrepancy. In this work, we used an experimental value of $343.7 \mathrm{kcal} / \mathrm{mol}$ (1 atm standard state) for the gas-phase acidity of HCN, which was taken from the NIST tables ${ }^{87}$ and is an average of two experimental determinations ${ }^{88,89}$ that are within $0.2 \mathrm{kcal} / \mathrm{mol}$ of one another. Except for this difference, the absolute solvation free energies reported in these two compilations are all within $1.0 \mathrm{kcal} / \mathrm{mol}$.

\section{Performance of Continuum Solvation Models for Predicting Absolute Aqueous Solvation Free Energies of Ions}

All of the ion and ion-water cluster data that were previously used to parametrize and test the SM6 continuum solvation model ${ }^{14}$ are based on Zhan and Dixon's value ${ }^{26}$ of $-264.3 \mathrm{kcal} / \mathrm{mol}$ for the absolute aqueous solvation free energy of the proton. However, above we have suggested using Tissandier et al.'s value of $-265.9 \mathrm{kcal} / \mathrm{mol}$ for the absolute aqueous solvation free energy of the proton. Using the absolute aqueous solvation free energies determined in this work for the same 112 unclustered ions that were included in our previous data set, plus the absolute aqueous solvation free energies determined in this work for 31 clustered ions containing a single water molecule that were included in our previous data set, we retested the performance of the same continuum models that were tested as part of our previous work, namely, SM5.43R, ${ }^{16,32}$ SM6, ${ }^{14}$ and five variants of the Polarizable Continuum Model $^{90,91}$ (PCM): dielectric PCM (DPCM) of Gaussian $98^{92}$ (DPCM/98), ${ }^{90,93,94}$ DPCM of Gaussian $03^{95}$ (DPCM/03), ${ }^{96}$ conductor-like PCM (CPCM) of Gaussian 98 (CPCM/98), ${ }^{97-99} \mathrm{CPCM}$ of Gaussian 03 (CPCM/03), ${ }^{97,98,100}$ and the integral-equation-formalism PCM (IEF- 
PCM $)^{96,101-103}$ of Gaussian 03. The combinations of solvation approximation and basis set that we used are SM6/MPW25/basis, where MPW25 is the same as the mPW1PW91 functional of Barone and Adamo, ${ }^{104}$ which they also call mPW0, and basis is MIDI!6D, ${ }^{105,106} 6-31 \mathrm{G}(\mathrm{d}),{ }^{107} 6-31+\mathrm{G}(\mathrm{d}),{ }^{107}$ or $6-31+\mathrm{G}(\mathrm{d}, \mathrm{p}),{ }^{107}$ plus SM6/B3LYP/6-31+G(d,p), SM6/B3PW91/6-31+G(d,p), SM5.43R/MPW25/6-31+G(d,p), DPCM/98/HF/6-31G(d), DPCM/03/HF/6-31G(d), CPCM/98/HF/6-31G(d), CPCM/03/HF/6-31G(d); IEF-PCM/03/HF/6-31G(d), and IEF-PCM/03/MPW25/6-31+G(d,p). For all PCM calculations, we used the United Atom for Hartree-Fock (UAHF) method for assigning atomic radii ${ }^{108}$ the UAHF method was optimized for use with the HF/6-31G(d) level of theory ${ }^{108}$ and is the recommended method for predicting aqueous solvation free energies with PCM according to the Gaussian 03 manual. ${ }^{95}$ (Thus, with the exception of IEF-PCM/03/MPW25/6-31+G(d,p), the PCM methods listed above have been tested in a way that should allow them to perform at their best.) For SM5.43R and SM6, the radii are part of the model and are given in the original papers. ${ }^{14,16,32}$

Summarized in Table 10 is the performance of the continuum models listed above for calculating absolute aqueous solvation free energies of unclustered ions and of clustered ions containing up to a single water molecule. The mean unsigned errors (MUEs) in this table were calculated using two different sets of ionic solutes. The first set, which is also called the selectively clustered ion set, includes 31 clustered ions containing a single water molecule, plus 81 unclustered ions (i.e., ions that are included in this set as clustered ions are not included as their analogous bare ions). The 112 ions in this set are the same ones that we used to optimize the atomic radii used by our SM6 
model. ${ }^{14}$ We also calculated MUEs using all 112 of the unclustered ions from above, plus the 31 unclustered ions that were not included in the selectively clustered data set (143 total ions), and this is the second set of ionic solutes. Both of these sets of ionic solutes are subsets of the ionic data listed in Tables 8 and 9. A full list of the ionic solutes contained in each of these subsets is given in ref 14 . The criteria that we used for deciding which ions to include in this set as clustered ions have been explained in detail elsewhere ${ }^{14,57}$ and are based on the number of atoms in the ion and the magnitude of atomic charge concentrated on single exposed heteroatoms in the ion. We should point out that although we have provided a precise definition of these criteria elsewhere, they are necessarily arbitrary. Ideally, we would like to give a definite prescription for when one should include explicit water molecules in implicit solvation model calculations. However, it is not possible to do this in a way that covers the great diversity of possible cases that occur in applications, especially if one includes transition states or ions containing functionalities not present in typical data sets. For ions, we have suggested in previous papers ${ }^{14,57}$ that an explicit water molecule should be added whenever one wants to improve the accuracy, since adding an explicit water should almost always improve the accuracy when the effect is large but is relatively safe because it cannot make the accuracy much worse when the effect is small.

For each set of ionic solutes, MUEs were calculated using the absolute aqueous solvation free energies taken from our previous compilation ${ }^{14}$ and those taken from the compilation developed as part of this work. Thus, MUEs were calculated using a total of four different sets of absolute aqueous solvation free energies. 
The conclusions that we made using our previous data set of solvation free energies do not change when absolute aqueous solvation free energies taken from the updated data set are used. In particular, SM6 outperforms all of the continuum models against which it was tested; for the selectively clustered ion set, all levels of theory used with SM6 give MUEs of $3.7 \mathrm{kcal} / \mathrm{mol}$ or less, whereas the closest competing model is SM5.43R, which gives a MUE of $5.2 \mathrm{kcal} / \mathrm{mol}$ when tested against this set of ions. As before, clustering significantly improves the performance of SM6. For all levels of theory, SM6 gives MUEs that are at least $1 \mathrm{kcal} / \mathrm{mol}$ smaller for the selectively clustered ion set than for the full set of ions. When SM6 is used with diffuse basis functions, its performance is better when tested against our previous data set but only by a small amount $(0.2-0.3 \mathrm{kcal} / \mathrm{mol})$. For all other levels of theory, the overall performance of SM6 improves when tested against the updated absolute solvation free energies. Thus, although SM6 was originally developed for predicting absolute aqueous solvation free energies that are based on Zhan and Dixon's value of $-264.3 \mathrm{kcal} / \mathrm{mol}$ for the absolute aqueous solvation free energy of the proton, the performance of SM6 is also good (and in some cases even better) when the recommended value of $-265.9 \mathrm{kcal} / \mathrm{mol}$ is used for the absolute aqueous solvation free energy of the proton.

\section{Conclusions}

Augmenting conventional aqueous solvation free energies of monatomic ions taken from the literature with conventional aqueous solvation free energies of polyatomic ions determined using thermochemical cycles that involve $\mathrm{p} K_{\mathrm{a}}$, gas-phase acidity, neutral solvation data, and gas-phase clustering free energies, the cluster pair approximation has 
been used to obtain a value of $-266.1 \mathrm{kcal} / \mathrm{mol}$ for the absolute aqueous solvation free energy of the proton. This value is in good agreement with Tissandier et al.'s value of $-265.9 \mathrm{kcal} / \mathrm{mol}^{24}{ }^{24}$ which these workers obtained using the same approximation, applied to a much smaller set of ions. Thus, we agree with Camaioni and Schwerdtfeger ${ }^{43}$ and suggest using a value of $-265.9 \mathrm{kcal} / \mathrm{mol}$ for the absolute aqueous solvation free energy of the proton in all future applications.

By analyzing subsets of data containing different types of cations (monatomic cations, oxonium cations, or ammonium ions), we demonstrated the sensitivity of the cluster pair approximation to variations in the data set, particularly if analysis is restricted to singly clustered ions. Taking this behavior into consideration, along with the experimental uncertainties associated with the gas-phase free energy differences that are required to use the cluster pair approximation, we estimate an uncertainty of no less than $2 \mathrm{kcal} / \mathrm{mol}$ for the absolute aqueous solvation free energy of the proton.

Using Tissandier et al.'s value for the absolute aqueous solvation free energy of the proton, we updated and expanded our previous compilation ${ }^{14}$ of absolute aqueous solvation free energies of ions (which was based on Zhan and Dixon's value ${ }^{26}$ for the absolute aqueous solvation free energy of the proton). The resulting data set, which contains absolute aqueous solvation free energies for 121 unclustered ions (not including $\mathrm{H}^{+}$) and 147 absolute aqueous solvation free energies for 51 clustered ions containing up to, in some cases, 6 water molecules, is the most accurate and comprehensive data set of its type to date. Using absolute aqueous solvation free energies taken from this new data set, we retested the performance of the same continuum solvation models that were tested as part of our previous work. ${ }^{14}$ As before, SM6 outperforms all of the continuum models 
against which it was tested. Also as before, adding a single explicit water molecule to some ions greatly improves the accuracy of SM6. Comparing the results obtained here to our previous results reveals that when diffuse basis functions are used the overall performance of SM6 becomes worse by $0.3 \mathrm{kcal} / \mathrm{mol}$ or less when tested against the updated data set of solvation free energies. When nondiffuse basis functions are used, the performance of SM6 actually increases when tested against the updated data set. This is encouraging, because it shows that the parameters contained in SM6, which were originally developed based on Zhan and Dixon's value for the absolute aqueous solvation free energy of the proton, are also quite accurate when a value of $-265.9 \mathrm{kcal} / \mathrm{mol}$ is used for this quantity.

Acknowledgment. The authors are grateful to Don Camaioni and Michel Dupuis for stimulating conversations on the subject of this work. This work was supported by the National Institutes of Health training grant for Neuro-physical-computational Sciences, by the U. S. Army Research Office under the Multidisciplinary Research Program of the University Research Initiative through Grant No. DAAD19-02-1-0176, by the Minnesota Partnership for Biotechnology and Medical Genomics, by the National Science Foundation (Grant Nos. CHE02-03446 and CHE03-49122), and by the Office of Naval Research under Grant No. N 00014-05-01-0538.

Supporting Information Available: Tables of slopes, intercepts, and $Y_{\mathrm{i}}$ and $y_{i j}$ values for all of the cluster pair fits described in this article and B97-1/MG3S optimized 
geometries of all of the clustered ions used to test the continuum solvation models. This material is available free of charge via the Internet at http://pubs.acs.org.

\section{References and Notes}

(1) Giesen, D. J.; Chambers, C. C.; Hawkins, G. D.; Cramer, C. J.; Truhlar, D. G. Modeling Free Energies of Solvation and Transfer. In Computational Thermochemistry: Prediction and Estimation of Molecular Thermodynamics; ACS Symposium Series Volume 677; Irikura, K., Frurip, D. J., Eds.; American Chemical Society: Washington, DC, 1998; p 285.

(2) Winget, P.; Weber, E. J.; Cramer, C. J.; Truhlar, D. G. Phys. Chem. Chem. Phys. 2000, 2, 1231.

(3) Cramer, C. J.; Truhlar, D. G. In Free Energy Calculations in Rational Drug Design; Reddy, M. R., Erion, M. D., Eds.; Kluwer/Plenum: New York, 2001; pp 63.

(4) Baik, M.-H.; Friesner, R. A. J. Phys. Chem. A 2002, 106, 7407.

(5) Lewis, A.; Bumpus, J. A.; Truhlar, D. G.; Cramer, C. J. J. Chem. Educ. 2004, 81, 596.

(6) Cramer, C. J. Essentials of Computational Chemistry: Theories and Models, 2nd ed.; Wiley \& Sons: Chichester, U. K., 2004; p 386.

(7) Cabani, S.; Gianni, P.; Mollica, V.; Lepori, L. J. Solution Chem. 1981, 10, 563.

(8) Wagman, D. D. J. Phys. Chem. Ref. Data Suppl. 1982, 2, 11. 
(9) Abraham, M. H.; Whiting, G. S.; Fuchs, R.; Chambers, E. J. J. Chem.

Soc., Perkin Trans. 2 1990, 291.

(10) Leo, A. J. Masterfile from MedChem Software; BioByte Corp.:

Claremont, CA, 1994.

(11) Physical/Chemical Property Database (PHYSPROP); SRC Environmental Science Center: Syracuse, NY, 1994.

(12) Yaffe, D.; Cohen, Y.; Espinosa, G.; Arenas, A.; Giralt, F. J. Chem. Inf. Comput. Sci. 2003, 43, 85 .

(13) Sander, R. Henry's Law Constants. In NIST Chemistry WebBook; NIST Standard Reference Database Number 69; Linstrom, P. J., Mallard, W. G., Eds.; National Institute of Standards and Technology: Gaithersburg, MD, June 2005.

(14) Kelly, C. P.; Cramer, C. J.; Truhlar, D. G. J. Chem. Theory Comput. 2005, $1,1133$.

(15) Li, J.; Zhu, T.; Hawkins, G. D.; Winget, P.; Liotard, D. A.; Cramer, C. J.;

Truhlar, D. G. Theor. Chem. Acc. 1999, 103, 9.

(16) Thompson, J. D.; Cramer, C. J.; Truhlar, D. G. J. Phys. Chem. A 2004, $108,6532$.

(17) Klotz, I. M.; Rosenberg, R. M. Chemical Thermodynamics, 5th ed.; Wiley: New York, 1994; p 459.

(18) Guggenheim, E. A. J. Phys. Chem. 1929, 33, 842.

(19) Guggenheim, E. A. J. Phys. Chem. 1930, 34, 1540.

(20) Lewis, G. N.; Randall, M.; Pitzer, K. S.; Brewer, L. Thermodynamics, 2nd ed.; McGraw-Hill: New York, 1961; p 399. 
(21) Pliego Jr., J. R.; Riveros, J. M. Chem. Phys. Lett. 2000, 332, 597.

(22) Borin, L. L. Russ. J. Phys. Chem. 1991, 65, 1328. Translated from: Zhur.

Fizi. Khim. 1991, 65, 2517.

(23) Pliego, J. R., Jr.; Riveros, J. M. Phys. Chem. Chem. Phys. 2002, 4, 1622.

(24) Tissandier, M. D.; Cowen, K. A.; Feng, W. Y.; Gundlach, E.; Cohen, M. J.; Earhart, A. D.; Coe, J. V. J. Phys. Chem. A 1998, 102, 7787.

(25) Tissandier et al. report a value of $-264.0 \mathrm{kcal} / \mathrm{mol}$ for the absolute aqueous solvation free energy of the proton. These workers used a standard-state concentration of $1 \mathrm{bar}$ in the gas phase and $1 \mathrm{~mol} / \mathrm{L}$ in the aqueous phase. Converting to the standard state that uses a concentration of $1 \mathrm{~mol} / \mathrm{L}$ in both the gas and aqueous phases requires that 1.9 $\mathrm{kcal} / \mathrm{mol}$ be subtracted from this value. The use of a standard state in which the concentration does not change is a natural choice for theoretical work because then the entropy of translation in the gas phase cancels what Ben-Naim ${ }^{56}$ calls the entropy of liberation in the liquid-phase solution, and the free energy of solvation is directly related to the solute-solvent coupling.

(26) Zhan, C.-G.; Dixon, D. A. J. Phys. Chem. A 2001, 105, 11534.

(27) The following papers use Zhan and Dixon's value for the absolute aqueous solvation free energy of the proton to calculate absolute aqueous solvation free energies, acid dissociation constants, or redox potentials: (a) Zhan, C. G.; Dixon, D. A.; Sabri, M. I.; Kim, M. S.; Spencer, P. S. J. Am. Chem. Soc. 2002, 124, 2744. (b) Zhan, C. G.; Spencer, P.; Dixon, D. A. J. Phys. Chem. B 2003, 107, 2853. (c) Dixon, D. A.; Feller, D.; Zhan, C. G.; Francisco, J. S. Int. J. Mass Spectrom. 2003, 227, 421. (d) McKee, M. L. J. Phys. Chem. A 2003, 107, 6819. (e) Zhan, C. G.; Dixon, D. A. J. Phys. Chem. A 2004, 
108, 2020. (f) Zhan, C. G.; Spencer, P. S.; Dixon, D. A. J. Phys. Chem. B 2004, 108, 6098. (g) Datta, S. N.; Sudhamsu, J.; Pandey, A. J. Phys. Chem. B 2004, 108, 8007. (h) Alexeev, Y.; Windus, T. L.; Zhan, C. G.; Dixon, D. A. Int. J. Quantum Chem. 2005, 102, 775. (i) Pandey, A.; Datta, S. N. J. Phys. Chem. B 2005, 109, 9066. (j) Huang, X.; Zheng, F.; Crooks, P. A.; Dwoskin, L. P.; Zhan, C. G. J. Am. Chem. Soc. 2005, 127, 14401. (k)

Ford, M. J.; Hoft, R. C.; McDonagh, A. J. Phys. Chem. B 2005, 109, 20387. (1) Reference 14.

(28) Dahlke, E. E.; Cramer, C. J. J. Phys. Org. Chem. 2003, 16, 336.

(29) Palascak, M. W.; Shields, G. C. J. Phys. Chem. A 2004, 108, 3692.

(30) Winget, P.; Cramer, C. J.; Truhlar, D. G. Theor. Chem. Acc. 2004, 112, 217.

(31) Benassi, R.; Ferrarini, P.; Fontanesi, C.; Benedetti, L.; Paolucci, F. J. Electroanal. Chem. 2004, 564, 231.

(32) Thompson, D. J.; Cramer, C. J.; Truhlar, D. G. Theor. Chem. Acc. 2005, $113,107$.

(33) Martin, D.; Illa, O.; Baceirdo, A.; Bertrand, G.; Ortuño, R. M.; Branchadell, V. J. Org. Chem. 2005, 70, 5671.

(34) Boily, J. F.; Seward, T. M. J. Solution Chem. 2005, 34, 1167.

(35) Yang, P.; Murthy, P. P. N.; Brown, R. E. J. Am. Chem. Soc. 2005, 127, 15848.

(36) Cammuri, G.; Ferrarini, P.; Giovanardi, R.; Benassi, R.; Fontanesi, C. J. Electroanal. Chem. 2005, 585, 181.

(37) Coe, J. V. Chem. Phys. Lett. 1994, 229, 161. 
(38) Tawa, G. J.; Topol, I. A.; Burt, S. K.; Caldwell, R. A.; Rashin, A. A. J.

Chem. Phys. 1998, 109, 4852.

(39) Tuttle Jr., T. R.; Malaxos, S.; Coe, J. V. J. Phys. Chem. A 2002, 106, 925.

(40) Asthagiri, D.; Pratt, L. R.; Ashbaugh, H. S. J. Chem. Phys. 2003, 119, 2702.

(41) Grossfield, A.; Ren, P.; Ponder, J. W. J. Am. Chem. Soc. 2003, 125, 15671.

(42) Bartels, D. M.; Takahashi, K.; Cline, J. A.; Marin, T. W.; Jonah, C. D. J. Phys. Chem. A 2005, 109, 1299.

(43) Camaioni, D. M.; Scherdtfeger, C. A. J. Phys. Chem. A 2005, 109, 10795.

(44) Lamoureux, G.; Roux, B. J. Phys. Chem. B 2006, 110, 3308.

(45) Westpahl, E.; Pliego Jr., J. R. J. Chem. Phys. 2005, 123, 074508.

(46) Pearson, R. G. J. Am. Chem. Soc. 1986, 108, 6109.

(47) Florián, J.; Warshel, A. J. Phys. Chem. B 1997, 101, 5583.

(48) Dolney, D. M.; Hawkins, G. D.; Winget, P.; Liotard, D. A.; Cramer, C. J.;

Truhlar, D. G. J. Comput. Chem. 2000, 21, 340.

(49) Lim, C.; Bashford, D.; Karplus, M. J. Phys. Chem. 1991, 95, 5610.

(50) Lohmann, F. Z. Naturforsch., A: Phys. Sci. 1967, 22, 843.

(51) Gomer, R.; Tryson, G. J. Chem. Phys. 1977, 66, 4413.

(52) Gurevich, Y. Y.; Pleskov, Y. V. Sov. Electrochem. 1982, 18, 1315.

(53) Reiss, H.; Heller, A. J. Phys. Chem. 1985, 89, 4207.

(54) Trasatti, S. Pure Appl. Chem. 1986, 58, 955.

(55) Coe, J. V. Int. Rev. Phys. Chem. 2001, 20, 33. 
(56) Ben-Naim, A. Solvation Thermodynamics; Plenum: New York, 1987.

(57) Kelly, C. P.; Cramer, C. J.; Truhlar, D. G. J. Phys. Chem. A 2006, 110, 2493.

(58) Benjamin, L.; Gold, V. Trans. Faraday Soc. 1954, 50, 797.

(59) Rosseinsky, D. R. Chem. Rev. 1965, 65, 467.

(60) Fawcett, W. R. J. Phys. Chem. B 1999, 103, 11181.

(61) Bartness, J. E. J. Phys. Chem. 1994, 98, 6420.

(62) Pearson, R. G.; Dillon, R. L. J. Am. Chem. Soc. 1953, 75, 2439.

(63) Richard, J. P.; Williams, G.; Gao, J. J. Am. Chem. Soc. 1999, 121, 715.

(64) Keeports, D. J. Chem. Educ. 2005, 82, 999.

(65) Lewis, G. N.; Randall, M.; Pitzer, K. S.; Brewer, L. Thermodynamics, 2nd ed.; McGraw-Hill: New York, 1961; p 272.

(66) Meot-Ner, M. M.; Lias, S. G. Binding Energies Between Ions and Molecules, and the Thermochemistry of Cluster Ions. In NIST Chemistry WebBook; NIST Standard Reference Database Number 69; Linstrom, P. J., Mallard, W. G., Eds.; National Institute of Standards and Technology: Gaithersburg, MD, March 2003.

(67) Weis, P.; Kemper, P. R.; Bowers, M. T.; Xantheas, S. J. Am. Chem. Soc. 1999, $121,3531$.

(68) Hamprecht, F. A.; Cohen, A. J.; Tozer, D. J.; Handy, N. C. J. Chem. Phys. 1998, 109, 6264.

(69) Fast, P. L.; Sanchez, M. L.; Truhlar, D. G. Chem. Phys. Lett. 1999, 306, 407. 
(70) Cunningham, A. J.; Payzant, J. D.; Kebarle, P. J. Am. Chem. Soc. 1972, 94, 7627.

(71) Meot-Ner, M.; Speller, C. V. J. Phys. Chem. 1986, 90, 6616.

(72) Klots, C. E. J. Phys. Chem. 1981, 85, 3585.

(73) Asthagiri and co-workers ${ }^{40}$ argue that the electrostatic potential associated with creating a solute cavity in the solvent does not go to zero as the cavity becomes infinitely large. If this is indeed true, then the solvation free energies for even inifinitely large anion-water and cation-water clusters should differ.

(74) Zhao, Y.; Truhlar, D. G. J. Chem. Theory. Comput. 2005, 1, 415.

(75) Dahlke, E. E.; Truhlar, D. G. J. Phys. Chem. B 2005, 109, 15677.

(76) Zhao, Y.; Schultz, N. E.; Truhlar, D. G. J. Chem. Theory Comput. 2006, 2, 364.

(77) Johnson, E. R.; DiLabio, G. A. Chem. Phys. Lett. 2006, 419, 333.

(78) Pliego, J. R., Jr.; Riveros, J. M. J. Phys. Chem. B 2000, 104, 5155.

(79) The results from several recent bulk liquid simulations $40,41,80$ converge to a value for the absolute solvation free energy of the hydroxide anion that is close to -119 $\mathrm{kcal} / \mathrm{mol}$. Substituting this value into eq 10 and using experimental values for the aqueous solvation free energy of water $(-6.32 \mathrm{kcal} / \mathrm{mol}),{ }^{43}$ the $\mathrm{p} K_{\mathrm{a}}$ of water $(15.7)$, and the gas-phase acidity of water $(383.7 \mathrm{kcal} / \mathrm{mol})^{87}$ lead to a value of $-252 \mathrm{kcal} / \mathrm{mol}$ for the aqueous solvation free energy of the proton.

(80) Lange, E.; Mishchenki, K. P. Z. Phys. 1930, 149 (Abt. A), 1.

(81) Parsons, R. Mod. Aspects Electrochem. 1954, 1, 103.

(82) Randles, J. E. B. Trans. Faraday Soc. 1956, 52, 1573. 
(83) Case, B.; Parsons, R. Trans. Faraday Soc. 1967, 63, 1224.

(84) Sokhan, V. P.; Tildesley, D. J. Mol. Phys. 1997, 92, 625.

(85) Various experimental and theoretical values for the surface potential of the air-water interface are listed in the following papers: (a) Barraclough, C. G.; McTigue, P. T.; Ng, Y. L. J. Electroanal. Chem. 1992, 329, 9. (b) Paluch, M. Adv. Colloid Interface Sci. 2000, 84, 27.

(86) Hunter, E. P. L.; Lias, S. G. J. Phys. Chem. Ref. Data 1998, 27, 413.

(87) Lias, S. G.; Bartness, J. E.; Liebman, J. F.; Holmes, J. L.; Levin, R. D.; Mallard, W. G. Ion Energetics Data. In NIST Chemistry WebBook; NIST Standard Reference Database Number 69; Linstrom, P. J., Mallard, W. G., Eds.; National Institute of Standards and Technology: Gaithersburg MD, March 2003.

(88) Bartness, J. E.; Scott, J. A.; McIver, R. T., Jr. J. Am. Chem. Soc. 1979, $101,6047$.

(89) Bradford, S. E.; Kim, E. H.; Arnold, D. W.; Neumark, D. M. J. Chem. Phys. 1993, 98, 800 .

(90) Miertus, S.; Scrocco, E.; Tomasi, J. J. Chem. Phys. 1981, 55, 117.

(91) Tomasi, J. Application of Continuum Solvation Models Based on a Quantum Mechanical Hamiltonian. In Structure and Reactivity in Aqueous Solution, Cramer, C. J., Truhlar, D. G., Eds.; ACS Symposium Series Volume 568; American Chemical Society: Washington, DC, 1994; p 10.

(92) Frisch, M. J.; Trucks, G. W.; Schlegel, H. B.; Scuseria, G. E.; Robb, M. A.; Cheeseman, J. R.; Zakrzewski, V. G.; Montgomery, J. A., Jr.; Stratmann, R. E.; Burant, J. C.; Dapprich, S.; Millam, J. M.; Daniels, A. D.; Kudin, K. N.; Strain, M. C.; 
Farkas, O.; Tomasi, J.; Barone, V.; Cossi, M.; Cammi, R.; Mennucci, B.; Pomelli, C.;

Adamo, C.; Clifford, S.; Ochterski, J. W.; Petersson, G. A.; Ayala, P. Y.; Cui, Q.;

Morokuma, K.; Malick, D. K.; Rabuck, A. D.; Raghavachari, K.; Foresman, J. B.;

Cioslowski, J.; Ortiz, J. V.; Stefanov, B. B.; Liu, G.; Liashenko, A.; Piskorz, P.;

Komaromi, I.; Gomperts, R.; Martin, R. L.; Fox, D. J.; Keith, T.; Al-Laham, M. A.; Peng,

C. Y.; Nanayakkara, A.; Gonzalez, C.; Challacombe, M.; Gill, P. M. W.; Johnson, B.;

Chen, W.; Wong, M. W.; Andres, J. L.; Head-Gordon, M.; Replogle, E. S.; Pople, J. A.

Gaussian 98, revision A.11; Gaussian, Inc.: Pittsburgh, PA, 1998.

(93) Miertus, S.; Tomasi, J. Chem. Phys. 1982, 65, 239.

(94) Cossi, M.; Barone, V.; Cammi, R.; Tomasi, J. Chem. Phys. Lett. 1996, $255,327$.

(95) Frisch, M. J.; Trucks, G. W.; Schlegel, H. B.; Scuseria, G. E.; Robb, M. A.; Cheeseman, J. R.; Montgomery, J. A., Jr.; Vreven, T.; Kudin, K. N.; Burant, J. C.; Millam, J. M.; Iyengar, S. S.; Tomasi, J.; Barone, V.; Mennucci, B.; Cossi, M.;

Scalamani, G.; Rega, N.; Petersson, G. A.; Nagatsuji, H.; Hada, M.; Ehara, M.; Toyota, K.; Fukuda, R.; Hasegawa, J.; Ishida, M.; Nakajima, T.; Honda, Y.; Kitao, O.; Nakai, H.;

Klene, M.; Li, X.; Knox, J. E.; Hratchian, H. P.; Cross, J. B.; Adamo, C.; Jaramillo, J.;

Gomperts, R.; Stratmann, R. E.; Yazyev, O.; Austin, A. J.; Cammi, R.; Pomelli, C.;

Ochterski, J. W.; Ayala, P. Y.; Morokuma, K.; Voth, G. A.; Salvador, P.; Dannenberg, J.

J.; Zakrzewski, V. G.; Dapprich, S.; Daniels, A. D.; Strain, M. C.; Farkas, O.; Malick, D.

K.; Rabuck, A. D.; Raghavachari, K.; Foresman, J. B.; Ortiz, J. V.; Cui, Q.; Baboul, A.

G.; Clifford, S.; Cioslowski, J.; Stefanov, B. B.; Liu, G.; Liashenko, A.; Piskorz, P.;

Komaromi, I.; Martin, R. L.; Fox, D. J.; Keith, T.; Al-Laham, M. A.; Peng, C. Y.; 
Nanayakkara, A.; Challacombe, M.; Gill, P. M. W.; Johnson, B.; Chen, W.; Wong, M. W.; Gonzalez, C.; Pople, J. A. Gaussian 03, revision C.01; Gaussian, Inc.: Wallingford, CT, 2003.

(96) Cossi, M.; Scalamani, G.; Rega, N.; Barone, V. J. Chem. Phys. 2002, 117, 43.

(97) Klamt, A.; Schüürmann, G. J. Chem. Soc., Perkin Trans. 2 1993, 799.

(98) Andzelm, J.; Kölmel, C.; Klamt, A. J. Chem. Phys. 1995, 103, 9312.

(99) Barone, V.; Cossi, M. J. Phys. Chem. A 1998, 102, 1995.

(100) Cossi, M.; Rega, N.; Scalamani, G.; Barone, V. J. Comput. Chem. 2003, 24,669 .

(101) Mennucci, B.; Tomasi, J. J. Chem. Phys. 1997, 106, 5151.

(102) Cancés, M. T.; Mennucci, B.; Tomasi, J. J. Chem. Phys. 1997, 107, 3032.

(103) Cossi, M.; Barone, V.; Mennucci, B.; Tomasi, J. Chem. Phys. Lett. 1998, $286,253$.

(104) Adamo, C.; Barone, V. J. Chem. Phys. 1998, 108, 664.

(105) Easton, R. E.; Giesen, D. J.; Welch, A.; Cramer, C. J.; Truhlar, D. G. Theor. Chim. Acta 1996, 93, 281.

(106) Li, J.; Cramer, C. J.; Truhlar, D. G. Theor. Chim. Acta 1998, 99, 192.

(107) Hehre, W. J.; Radom, L.; Schleyer, P. v. R.; Pople, J. A. Ab Initio Molecular Orbital Theory; Wiley: New York, 1986.

(108) Barone, V.; Cossi, M.; Tomasi, J. J. Chem. Phys. 1997, 107, 3210. 
TABLE 1: Conventional Aqueous Solvation Free Energies of Monatomic

Ions (kcal/mol) ${ }^{a}$

\begin{tabular}{|c|c|c|}
\hline $\mathrm{M}^{ \pm}$ & Fawcett $^{b}$ & Tissandier et al. $^{c}$ \\
\hline $\mathrm{H}^{+}$ & 0 & 0 \\
\hline $\mathrm{Li}^{+}$ & 137.5 & 137.5 \\
\hline $\mathrm{Na}^{+}$ & 162.7 & 162.7 \\
\hline $\mathrm{K}^{+}$ & 179.9 & 179.9 \\
\hline $\mathrm{Rb}^{+}$ & 185.3 & 185.3 \\
\hline $\mathrm{Cs}^{+}$ & 190.8 & \\
\hline $\mathrm{Tl}^{+}$ & 178.3 & \\
\hline $\mathrm{Cu}^{+}$ & 124.6 & \\
\hline $\mathrm{Ag}^{+}$ & 147.2 & \\
\hline $\mathrm{F}^{-}$ & -370.3 & -370.3 \\
\hline $\mathrm{Cl}^{-}$ & -340.4 & -340.5 \\
\hline $\mathrm{Br}^{-}$ & -334.2 & -334.1 \\
\hline $\mathrm{I}^{-}$ & -325.8 & -325.2 \\
\hline $\mathrm{OH}^{-}$ & & -370.7 \\
\hline \multicolumn{3}{|c|}{$\begin{array}{l}\quad{ }^{a} \text { All conventional free energies are for a } \\
\text { temperature of } 298 \mathrm{~K} \text { and use a standard- } \\
\text { state concentration of } 1 \mathrm{~mol} / \mathrm{L} \text { in both the gas } \\
\text { and the aqueous phases. }{ }^{b} \text { Reference } 60 \text {. } \\
{ }^{c} \text { Reference } 24 \text {. }\end{array}$} \\
\hline
\end{tabular}


TABLE 2: Conventional Aqueous Solvation Free Energies of Cations (kcal $/ \mathrm{mol})^{a}$

\begin{tabular}{|c|c|c|c|c|c|}
\hline $\mathrm{BH}^{+}$ & $\mathrm{B}$ & $\Delta G_{\mathrm{g}}^{\circ}\left(\mathrm{BH}^{+}\right)^{b}$ & $\Delta G_{\mathrm{S}}^{*}(\mathrm{~B})^{c}$ & $\mathrm{p} K_{\mathrm{a}}\left(\mathrm{BH}^{+}\right)^{d}$ & $\Delta G_{\mathrm{S}}^{*, \operatorname{con}}\left(\mathrm{BH}^{+}\right)^{e}$ \\
\hline $\mathrm{H}_{3} \mathrm{O}^{+}$ & water & 157.7 & -6.3 & -1.7 & 155.6 \\
\hline $\mathrm{CH}_{3} \mathrm{OH}_{2}^{+}$ & methanol & 173.2 & -5.1 & -2.1 & 172.9 \\
\hline $\mathrm{CH}_{3} \mathrm{CH}_{2} \mathrm{OH}_{2}^{+}$ & ethanol & 178.0 & -5.0 & -1.9 & 177.5 \\
\hline$\left(\mathrm{CH}_{3}\right)_{2} \mathrm{OH}^{+}$ & dimethyl ether & 182.7 & -1.8 & -2.5 & 186.2 \\
\hline$\left(\mathrm{C}_{2} \mathrm{H}_{5}\right)_{2} \mathrm{OH}^{+}$ & diethyl ether & 191.0 & -1.8 & -2.4 & 194.4 \\
\hline $\mathrm{CH}_{3} \mathrm{C}(\mathrm{OH}) \mathrm{CH}_{3}{ }^{+}$ & acetone & 186.9 & -3.9 & -2.9 & 188.8 \\
\hline $\mathrm{CH}_{3} \mathrm{C}(\mathrm{OH}) \mathrm{C}_{6} \mathrm{H}_{5}{ }^{+}$ & acetophenone & 198.2 & -4.6 & -4.3 & 201.4 \\
\hline $\mathrm{NH}_{4}^{+}$ & ammonia & 195.7 & -4.3 & 9.3 & 180.7 \\
\hline $\mathrm{CH}_{3} \mathrm{NH}_{3}^{+}$ & methylamine & 206.6 & -4.6 & 10.6 & 189.5 \\
\hline $\mathrm{CH}_{3}\left(\mathrm{CH}_{2}\right)_{2} \mathrm{NH}_{3}^{+}$ & $n$-propylamine & 211.3 & -4.4 & 10.6 & 194.4 \\
\hline$\left(\mathrm{CH}_{3}\right)_{2} \mathrm{CHNH}_{3}^{+}$ & isopropylamine & 212.5 & -3.7 & 10.6 & 196.3 \\
\hline $\mathrm{C}\left(\mathrm{CH}_{3}\right)_{3} \mathrm{NH}_{3}^{+}$ & $t$-butylamine & 215.1 & -3.9 & 10.7 & 198.6 \\
\hline$c-\mathrm{C}_{6} \mathrm{H}_{11} \mathrm{NH}_{3}^{+}$ & cyclohexanamine & 215.0 & -5.1 & 10.7 & 197.2 \\
\hline $\mathrm{H}_{2} \mathrm{C}=\mathrm{CHCH}_{2} \mathrm{NH}_{3}{ }^{+}$ & allylamine & 209.2 & -4.3 & 9.5 & 193.9 \\
\hline$\left(\mathrm{CH}_{3}\right)_{2} \mathrm{NH}_{2}^{+}$ & dimethylamine & 214.3 & -4.3 & 10.7 & 197.3 \\
\hline$\left(\mathrm{C}_{2} \mathrm{H}_{5}\right)_{2} \mathrm{NH}_{2}^{+}$ & diethylamine & 219.7 & -4.1 & 11.0 & 202.5 \\
\hline$\left(n-\mathrm{C}_{3} \mathrm{H}_{7}\right)_{2} \mathrm{NH}_{2}^{+}$ & di- $n$-propylamine & 222.1 & -3.7 & 11.0 & 205.4 \\
\hline$\left(\mathrm{H}_{2} \mathrm{C}=\mathrm{CHCH}_{2}\right)_{2} \mathrm{NH}_{2}{ }^{+}$ & diallylamine & 219.0 & -4.0 & 9.3 & 204.3 \\
\hline$\left(\mathrm{CH}_{3}\right)_{3} \mathrm{NH}^{+}$ & trimethylamine & 219.4 & -3.2 & 9.8 & 204.8 \\
\hline$\left(\mathrm{C}_{2} \mathrm{H}_{5}\right)_{3} \mathrm{NH}^{+}$ & triethylamine & 227.0 & -3.0 & 10.8 & 211.3 \\
\hline$\left(n-\mathrm{C}_{3} \mathrm{H}_{7}\right)_{3} \mathrm{NH}^{+}$ & tri- $n$-propylamine & 229.5 & -2.5 & 10.3 & 215.0 \\
\hline $\mathrm{C}_{6} \mathrm{H}_{5} \mathrm{NH}_{3}^{+}$ & aniline & 203.3 & -5.5 & 4.6 & 193.5 \\
\hline
\end{tabular}




\begin{tabular}{|c|c|c|c|c|c|}
\hline$o-\mathrm{CH}_{3} \mathrm{C}_{6} \mathrm{H}_{4} \mathrm{NH}_{3}^{+}$ & 2-methylaniline & 205.3 & -5.6 & 4.5 & 195.6 \\
\hline$m-\mathrm{CH}_{3} \mathrm{C}_{6} \mathrm{H}_{4} \mathrm{NH}_{3}{ }^{+}$ & 3-methylaniline & 206.5 & -5.7 & 4.7 & 196.3 \\
\hline$p-\mathrm{CH}_{3} \mathrm{C}_{6} \mathrm{H}_{4} \mathrm{NH}_{3}^{+}$ & 4-methylaniline & 206.7 & -5.6 & 5.1 & 196.1 \\
\hline$m-\mathrm{NH}_{2} \mathrm{C}_{6} \mathrm{H}_{4} \mathrm{NH}_{3}{ }^{+}$ & 3-aminoaniline & 214.9 & -9.9 & 5.0 & 200.1 \\
\hline $\mathrm{C}_{6} \mathrm{H}_{5} \mathrm{NH}_{2} \mathrm{CH}_{3}^{+}$ & $N$-methylaniline & 212.7 & -4.7 & 4.9 & 203.3 \\
\hline $\mathrm{C}_{6} \mathrm{H}_{5} \mathrm{NH}_{2} \mathrm{CH}_{2} \mathrm{CH}_{3}^{+}$ & $N$-ethylaniline & 213.4 & -4.6 & 5.1 & 203.7 \\
\hline $\mathrm{C}_{6} \mathrm{H}_{5} \mathrm{NH}\left(\mathrm{CH}_{3}\right)_{2}^{+}$ & $N, N$-dimethylaniline & 217.3 & -3.6 & 5.1 & 208.7 \\
\hline$p-\mathrm{CH}_{3} \mathrm{C}_{6} \mathrm{H}_{4} \mathrm{NH}\left(\mathrm{CH}_{3}\right)_{2}{ }^{+}$ & 4-methyl- $N, N$-dimethylaniline & 219.4 & -3.7 & 5.6 & 210.0 \\
\hline $\mathrm{C}_{6} \mathrm{H}_{5} \mathrm{NH}\left(\mathrm{CH}_{2} \mathrm{CH} 3\right)_{2}^{+}$ & $N, N$-diethylaniline & 221.8 & -2.9 & 6.6 & 211.9 \\
\hline $\mathrm{C}_{10} \mathrm{H}_{7} \mathrm{NH}_{3}^{+}$ & 1-aminonaphthalene & 209.2 & -7.3 & 3.9 & 198.5 \\
\hline $\mathrm{C}_{2} \mathrm{H}_{4} \mathrm{NH}_{2}^{+}$ & aziridine & 208.5 & -4.5 & 8.0 & 195.0 \\
\hline $\mathrm{C}_{3} \mathrm{H}_{6} \mathrm{NH}_{2}^{+}$ & azetidine & 217.2 & -5.6 & 11.3 & 198.2 \\
\hline $\mathrm{C}_{4} \mathrm{H}_{8} \mathrm{NH}_{2}^{+}$ & pyrrolidine & 218.8 & -5.5 & 11.3 & 199.9 \\
\hline $\mathrm{C}_{5} \mathrm{H}_{10} \mathrm{NH}_{2}^{+}$ & piperidine & 220.0 & -5.1 & 11.1 & 201.7 \\
\hline $\mathrm{C}_{6} \mathrm{H}_{12} \mathrm{NH}_{2}^{+}$ & azacycloheptane & 220.7 & -4.9 & 11.1 & 202.6 \\
\hline $\mathrm{C}_{4} \mathrm{H}_{5} \mathrm{NH}^{+}$ & pyrrole & 201.7 & -4.3 & -3.8 & 204.5 \\
\hline Pyridine $^{+}$ & pyridine & 214.7 & -4.7 & 5.2 & 204.8 \\
\hline $\mathrm{C}_{9} \mathrm{H}_{7} \mathrm{NH}^{+}$ & quinoline & 220.2 & -5.7 & 4.8 & 209.9 \\
\hline $\mathrm{C}_{4} \mathrm{H}_{8} \mathrm{NHNH}_{2}^{+}$ & piperazine & 218.6 & -7.4 & 9.7 & 199.9 \\
\hline $\mathrm{CH}_{3} \mathrm{CNH}^{+}$ & acetonitrile & 179.0 & -3.9 & -10.0 & 190.6 \\
\hline $\mathrm{H}_{2} \mathrm{NNH}_{3}^{+}$ & hydrazine & 196.6 & -6.3 & 8.1 & 181.3 \\
\hline$p-\mathrm{CH}_{3} \mathrm{OC}_{6} \mathrm{H}_{4} \mathrm{NH}_{3}{ }^{+}$ & 4-methoxyaniline & 207.6 & -7.6 & 5.3 & 194.7 \\
\hline$p-\mathrm{NO}_{2} \mathrm{C}_{6} \mathrm{H}_{4} \mathrm{NH}_{3}^{+}$ & 4-nitroaniline & 199.4 & -9.9 & 1.0 & 190.0 \\
\hline $\mathrm{C}_{4} \mathrm{H}_{8} \mathrm{ONH}_{2}^{+}$ & morpholine & 213.0 & -7.2 & 8.4 & 196.3 \\
\hline $\mathrm{CH}_{3} \mathrm{COHNH}_{2}^{+}$ & acetamide & 199.0 & -9.7 & -0.6 & 192.0 \\
\hline $\mathrm{C}_{6} \mathrm{H}_{5} \mathrm{COHNH}_{2}^{+}$ & benzamide & 205.8 & -10.9 & -1.4 & 198.7 \\
\hline
\end{tabular}




\begin{tabular}{|c|c|c|c|c|c|}
\hline$\left(\mathrm{CH}_{3}\right)_{2} \mathrm{SH}^{+}$ & dimethyl sulfide & 191.5 & -1.5 & -7.0 & 201.4 \\
\hline$\left(\mathrm{CH}_{3}\right)_{2} \mathrm{SOH}^{+}$ & dimethyl sulfoxide & 204.0 & -9.8 & -1.5 & 198.2 \\
\hline$m-\mathrm{ClC}_{6} \mathrm{H}_{4} \mathrm{NH}_{3}^{+}$ & 3-chloroaniline & 199.9 & -5.8 & 3.5 & 191.2 \\
\hline$p-\mathrm{ClC}_{6} \mathrm{H}_{4} \mathrm{NH}_{3}^{+}$ & 4-chloroaniline & 201.2 & -5.9 & 4.0 & 191.8 \\
\hline
\end{tabular}

${ }^{a}$ All data are for a temperature of $298 \mathrm{~K}$. Auxiliary data were taken from from ref $14 .{ }^{b}$ Gas-phase acidity of the ionic species, for a standard-state gas-phase pressure of $1 \mathrm{~atm} .{ }^{c}$ Absolute aqueous solvation free energy of the neutral species for a standard-state concentration of $1 \mathrm{~mol} / \mathrm{L}$ in both the gas and the aqueous phases. ${ }^{\mathrm{p}} K_{\mathrm{a}}$ of the ionic species.

${ }^{e}$ Conventional aqueous solvation free energy of the ion for a standard-state concentration of $1 \mathrm{~mol} / \mathrm{L}$ in both the gas and the aqueous phases. 
TABLE 3: Conventional Aqueous Solvation Free Energies of Anions (kcal/mol) ${ }^{a}$

\begin{tabular}{|c|c|c|c|c|c|}
\hline $\mathrm{A}^{-}$ & $\mathrm{AH}$ & $\Delta G_{\mathrm{g}}^{\circ}(\mathrm{AH})^{b}$ & $\Delta G_{\mathrm{S}}^{*}(\mathrm{AH})^{c}$ & $\mathrm{p} K_{\mathrm{a}}(\mathrm{AH})^{d}$ & $\Delta G_{\mathrm{S}}^{*, \operatorname{con}}\left(\mathrm{A}^{-}\right)^{e}$ \\
\hline $\mathrm{OH}^{-}$ & water & 383.7 & -6.3 & 15.7 & -370.6 \\
\hline $\mathrm{HO}_{2}^{-}$ & hydrogen peroxide & 368.6 & -8.6 & 11.7 & -363.2 \\
\hline $\mathrm{O}_{2}^{-}$ & hydroperoxyl radical & 346.7 & -7.0 & 4.7 & -349.2 \\
\hline $\mathrm{HS}^{-}$ & hydrogen sulfide & 344.9 & -0.7 & 7.0 & -338.0 \\
\hline $\mathrm{HC}_{2}^{-}$ & acetylene & 370.0 & 0.0 & 21.7 & -342.4 \\
\hline $\mathrm{CN}^{-}$ & hydrogen cyanide & 343.7 & -3.1 & 9.2 & -336.1 \\
\hline $\mathrm{CH}_{3} \mathrm{O}^{-}$ & methanol & 375.0 & -5.1 & 15.5 & -360.9 \\
\hline $\mathrm{C}_{2} \mathrm{H}_{5} \mathrm{O}^{-}$ & ethanol & 371.3 & -5.0 & 15.9 & -356.6 \\
\hline $\mathrm{CH}_{3} \mathrm{CH}_{2} \mathrm{CH}_{2} \mathrm{O}^{-}$ & 1-propanol & 369.4 & -4.8 & 16.1 & -354.2 \\
\hline$\left(\mathrm{CH}_{3}\right)_{2} \mathrm{CHO}^{-}$ & 2-propanol & 368.8 & -4.8 & 17.1 & -352.2 \\
\hline $\mathrm{CH}_{3} \mathrm{CH}_{2} \mathrm{CHOCH}_{3}{ }^{-}$ & 2-butanol & 367.5 & -4.7 & 17.6 & -350.1 \\
\hline $\mathrm{C}\left(\mathrm{CH}_{3}\right)_{3} \mathrm{O}^{-}$ & $t$-butanol & 367.9 & -4.5 & 19.2 & -348.2 \\
\hline $\mathrm{H}_{2} \mathrm{C}=\mathrm{CHCH}_{2} \mathrm{O}^{-}$ & allyl alcohol & 366.6 & -5.1 & 15.5 & -352.5 \\
\hline $\mathrm{CH}_{3} \mathrm{OCH}_{2} \mathrm{CH}_{2} \mathrm{O}^{-}$ & 2-methoxyethanol & 366.8 & -6.8 & 14.8 & -355.3 \\
\hline $\mathrm{HOCH}_{2} \mathrm{CH}_{2} \mathrm{O}^{-}$ & 1,2-ethanediol & 360.9 & -9.3 & 15.4 & -351.2 \\
\hline $\mathrm{C}_{6} \mathrm{H}_{5} \mathrm{CH}_{2} \mathrm{O}^{-}$ & benzyl alcohol & 363.4 & -6.6 & 15.4 & -351.0 \\
\hline $\mathrm{CF}_{3} \mathrm{CH}_{2} \mathrm{O}^{-}$ & 2,2,2-trifluoroethanol & 354.1 & -4.3 & 12.4 & -343.4 \\
\hline $\mathrm{CH}\left(\mathrm{CF}_{3}\right)_{2} \mathrm{O}^{-}$ & 1,1,1,3,3,3-hexafluoropropan-2-ol & 338.4 & -3.8 & 9.3 & -331.4 \\
\hline $\mathrm{CH}_{3} \mathrm{OO}^{-}$ & methyl hydroperoxide & 367.6 & -5.3 & 11.5 & -359.1 \\
\hline $\mathrm{CH}_{3} \mathrm{CH}_{2} \mathrm{OO}^{-}$ & ethyl hydroperoxide & 363.9 & -5.3 & 11.8 & -355.1 \\
\hline $\mathrm{HCO}_{2}^{-}$ & formic acid & 338.3 & -7.0 & 3.8 & -342.1 \\
\hline $\mathrm{CH}_{3} \mathrm{CO}_{2}^{-}$ & acetic acid & 341.4 & -6.7 & 4.8 & -343.5 \\
\hline $\mathrm{CH}_{3} \mathrm{CH}_{2} \mathrm{CO}_{2}^{-}$ & propanoic acid & 340.4 & -6.5 & 4.9 & -342.1 \\
\hline $\mathrm{CH}_{3}\left(\mathrm{CH}_{2}\right)_{4} \mathrm{CO}_{2}^{-}$ & hexanoic acid & 339.0 & -6.2 & 4.9 & -340.5 \\
\hline
\end{tabular}




\begin{tabular}{|c|c|}
\hline $\mathrm{H}_{2} \mathrm{C}=\mathrm{CHCO}_{2}^{-}$ & acrylic acid \\
\hline $\mathrm{CH}_{3} \mathrm{COCO}_{2}^{-}$ & pyruvic acid \\
\hline $\mathrm{CH}_{2} \mathrm{ClCO}_{2}^{-}$ & chloroacetic acid \\
\hline $\mathrm{CHCl}_{2} \mathrm{CO}_{2}^{-}$ & dichloroacetic acid \\
\hline $\mathrm{CF}_{3} \mathrm{CO}_{2}^{-}$ & trifluoroacetic acid \\
\hline $\mathrm{C}_{6} \mathrm{H}_{5} \mathrm{CO}_{2}^{-}$ & benzoic acid \\
\hline $\mathrm{C}_{6} \mathrm{H}_{5} \mathrm{O}^{-}$ & phenol \\
\hline$o-\mathrm{CH}_{3} \mathrm{C}_{6} \mathrm{H}_{4} \mathrm{O}^{-}$ & 2-methylphenol \\
\hline$m-\mathrm{CH}_{3} \mathrm{C}_{6} \mathrm{H}_{4} \mathrm{O}^{-}$ & 3-methylphenol \\
\hline$p-\mathrm{CH}_{3} \mathrm{C}_{6} \mathrm{H}_{4} \mathrm{O}^{-}$ & 4-methylphenol \\
\hline$m-\mathrm{HOC}_{6} \mathrm{H}_{4} \mathrm{O}^{-}$ & 3-hydroxyphenol \\
\hline$p-\mathrm{HOC}_{6} \mathrm{H}_{4} \mathrm{O}^{-}$ & 4-hydroxyphenol \\
\hline$o-\mathrm{NO}_{2} \mathrm{C}_{6} \mathrm{H}_{4} \mathrm{O}^{-}$ & 2-nitrophenol \\
\hline$m-\mathrm{NO}_{2} \mathrm{C}_{6} \mathrm{H}_{4} \mathrm{O}^{-}$ & 3-nitrophenol \\
\hline$p-\mathrm{NO}_{2} \mathrm{C}_{6} \mathrm{H}_{4} \mathrm{O}^{-}$ & 4-nitrophenol \\
\hline$o-\mathrm{ClC}_{6} \mathrm{H}_{4} \mathrm{O}^{-}$ & 2-chlorophenol \\
\hline$p-\mathrm{ClC}_{6} \mathrm{H}_{4} \mathrm{O}^{-}$ & 4-chlorophenol \\
\hline $\mathrm{CH}_{2}(\mathrm{O}) \mathrm{CH}^{-}$ & acetaldehyde \\
\hline $\mathrm{CH}_{3} \mathrm{C}(\mathrm{O}) \mathrm{CH}_{2}^{-}$ & acetone \\
\hline $\mathrm{CH}_{3} \mathrm{CH}_{2} \mathrm{C}(\mathrm{O}) \mathrm{CHCH}_{3}^{-}$ & 3-pentanone \\
\hline $\mathrm{NCNH}^{-}$ & cyanamide \\
\hline $\mathrm{CH}_{2} \mathrm{CN}^{-}$ & acetonitrile \\
\hline $\mathrm{C}_{6} \mathrm{H}_{5} \mathrm{NH}^{-}$ & aniline \\
\hline$p-\mathrm{NO}_{2} \mathrm{C}_{6} \mathrm{H}_{5} \mathrm{NH}^{-}$ & 4-nitroaniline \\
\hline$\left(\mathrm{C}_{6} \mathrm{H}_{5}\right)_{2} \mathrm{~N}^{-}$ & diphenylamine \\
\hline $\mathrm{CH}_{3} \mathrm{CONH}^{-}$ & acetamide \\
\hline $\mathrm{CH}_{2} \mathrm{NO}_{2}^{-}$ & nitromethane \\
\hline
\end{tabular}

$\begin{array}{lrrr}337.2 & -6.6 & 4.3 & -339.9 \\ 326.5 & -9.4 & 2.5 & -334.4 \\ 328.9 & -8.7 & 2.9 & -335.6 \\ 321.5 & -6.6 & 1.4 & -328.2 \\ 316.7 & -7.3 & 0.5 & -325.2 \\ 333.0 & -7.9 & 4.2 & -337.1 \\ 342.9 & -6.6 & 10.0 & -337.8 \\ 342.4 & -5.9 & 10.3 & -336.1 \\ 343.3 & -5.5 & 10.1 & -337.0 \\ 343.8 & -6.1 & 10.3 & -337.9 \\ 339.1 & -11.4 & 9.3 & -339.7 \\ 343.1 & -11.9 & 9.9 & -343.5 \\ 329.5 & -4.5 & 7.2 & -326.0 \\ 327.6 & -9.6 & 8.4 & -327.8 \\ 320.9 & -10.6 & 7.1 & -323.7 \\ 337.1 & -4.5 & 8.5 & -332.0 \\ 336.5 & -6.2 & 9.4 & -331.9 \\ 359.4 & -3.5 & 16.5 & -342.4 \\ 362.2 & -3.9 & 19.0 & -342.1 \\ 361.4 & -3.3 & 19.9 & -339.6 \\ 344.0 & -6.2 & 10.3 & -338.1 \\ 366.0 & -3.9 & 28.9 f & -332.5 \\ 359.1 & -5.5 & 27.7 & -328.8 \\ 336.2 & -9.9 & 18.2 & -323.3 \\ 343.8 & -5.3 & 22.4 & -320.5 \\ 355.0 & -9.7 & 15.1 & -346.1 \\ 350.4 & -4.0 & 10.2 & -342.4\end{array}$




$\begin{array}{llrrrr}\mathrm{CH}_{3} \mathrm{~S}^{-} & \text {methanethiol } & 350.6 & -1.2 & 10.3 & -339.7 \\ \mathrm{CH}_{3} \mathrm{CH}_{2} \mathrm{~S}^{-} & \text {ethanethiol } & 348.9 & -1.3 & 10.6 & -337.7 \\ \mathrm{C}_{3} \mathrm{H}_{7} \mathrm{~S}^{-} & \text {1-propanethiol } & 347.9 & -1.1 & 10.7 & -336.4 \\ \mathrm{C}_{6} \mathrm{H}_{5} \mathrm{~S}^{-} & \text {thiophenol } & 333.8 & -2.6 & 6.6 & -329.3 \\ \mathrm{CH}_{3} \mathrm{~S}(\mathrm{O}) \mathrm{CH}_{2}{ }^{-} & \text {dimethyl sulfoxide } & 366.8 & -9.8 & 33.0 & -333.6 \\ \mathrm{CCl}_{3}^{-} & \text {chloroform } & 349.7 & -1.1 & 24.0 & -320.0\end{array}$

${ }^{a}$ All data are for a temperature of $298 \mathrm{~K}$. Auxiliary data were taken from from ref 14, unless otherwise indicated. ${ }^{b}$ Gas-phase acidity of the neutral species, for a standard-state gas-phase pressure of $1 \mathrm{~atm}$. ${ }^{c}$ Absolute aqueous solvation free energy of the neutral species for a standard-state concentration of $1 \mathrm{~mol} / \mathrm{L}$ in both the gas and the aqueous phases. $d_{\mathrm{p}} K_{\mathrm{a}}$ of the neutral species. ${ }^{e}$ Conventional aqueous solvation free energy of the ion for a standard-state concentration of $1 \mathrm{~mol} / \mathrm{L}$ in both the gas and the aqueous phases. $f$ Reference 63. 
TABLE 4: Gas-Phase Clustering Free Energies of Ion-Water Clusters (kcal/mol) ${ }^{a}$

\begin{tabular}{|c|c|c|c|c|c|c|}
\hline \multirow[b]{2}{*}{$\mathrm{M}^{ \pm}$} & \multicolumn{6}{|c|}{$\Delta G_{i-1, i}^{\circ}\left(\mathrm{M}^{ \pm}\right)^{b}$} \\
\hline & 0,1 & 1,2 & 2,3 & 3,4 & 4,5 & 5,6 \\
\hline $\mathrm{Li}^{+}$ & -27.2 & -18.9 & -13.3 & -7.5 & -4.5 & -2.5 \\
\hline $\mathrm{Na}^{+}$ & -18.8 & -13.2 & -9.0 & -5.9 & -3.6 & -2.9 \\
\hline $\mathrm{K}^{+}$ & -11.8 & -8.9 & -6.3 & -4.4 & -3.2 & -2.3 \\
\hline $\mathrm{Rb}^{+}$ & -9.8 & -7.0 & -5.0 & -3.8 & -2.8 & \\
\hline $\mathrm{Cs}^{+}$ & $-7.9^{c}$ & $-5.9^{c}$ & $-4.1^{c}$ & $-3.0^{c}$ & & \\
\hline $\mathrm{Ag}^{+}$ & $-24.8^{d}$ & $-18.8^{d}$ & $-8.6^{d}$ & $-6.1^{d}$ & $-4.7^{d}$ & $-3.7^{d}$ \\
\hline $\mathrm{H}_{3} \mathrm{O}^{+}$ & $-24.5^{e, f}$ & $-12.9^{e, f}$ & $-9.5^{e, f}$ & $-5.7^{e, g}$ & $-4.4^{e, f}$ & $-2.9^{e}$ \\
\hline $\mathrm{CH}_{3} \mathrm{OH}_{2}^{+}$ & $-18.5^{h}$ & $-12.4^{i}$ & $-7.1^{i}$ & $-5.0^{i}$ & $-3.6^{i}$ & $-2.8^{i}$ \\
\hline $\mathrm{CH}_{3} \mathrm{CH}_{2} \mathrm{OH}_{2}^{+}$ & $-16.8^{h}$ & $-10.9^{j}$ & $-6.5^{j}$ & $-4.8^{j}$ & & \\
\hline$\left(\mathrm{CH}_{3}\right)_{2} \mathrm{OH}^{+}$ & $-15.4^{h}$ & & & & & \\
\hline $\mathrm{CH}_{3} \mathrm{C}(\mathrm{OH}) \mathrm{CH}_{3}{ }^{+}$ & $-12.8^{h}$ & $-6.7^{i}$ & $-6.2^{i}$ & $-4.3^{i}$ & $-3.3^{i}$ & \\
\hline $\mathrm{CH}_{3} \mathrm{C}(\mathrm{OH}) \mathrm{C}_{6} \mathrm{H}_{5}^{+}$ & $-10.8^{h}$ & & & & & \\
\hline $\mathrm{NH}_{4}^{+}$ & $-12.6^{h}$ & $-8.6^{e, k, l}$ & $-6.2^{e, i, k, l}$ & $-4.3^{i, k, l}$ & $-2.8^{i, k}$ & \\
\hline $\mathrm{CH}_{3} \mathrm{NH}_{3}^{+}$ & $-10.7^{i, l, m}$ & $-7.2^{i, l, m}$ & $-5.0^{i, l, m}$ & $-3.7^{m}$ & & \\
\hline $\mathrm{CH}_{3}\left(\mathrm{CH}_{2}\right)_{2} \mathrm{NH}_{3}{ }^{+}$ & $-8.7^{i}$ & $-5.3^{i}$ & $-3.4^{i}$ & $-2.5^{i}$ & & \\
\hline$\left(\mathrm{CH}_{3}\right)_{2} \mathrm{NH}_{2}^{+}$ & $-8.7^{i, l}$ & $-6.2^{i, l}$ & $-4.1^{i, l}$ & $-3.0^{i}$ & $-2.1^{i}$ & \\
\hline$\left(\mathrm{CH}_{3}\right)_{3} \mathrm{NH}^{+}$ & $-7.5^{i, l}$ & $-4.2^{i, l}$ & $-3.0^{i, l}$ & & & \\
\hline$\left(\mathrm{C}_{2} \mathrm{H}_{5}\right)_{3} \mathrm{NH}^{+}$ & $-5.1^{n}$ & & & & & \\
\hline$\left(n-\mathrm{C}_{3} \mathrm{H}_{7}\right)_{3} \mathrm{NH}^{+}$ & $-3.5^{n}$ & & & & & \\
\hline $\mathrm{C}_{4} \mathrm{H}_{8} \mathrm{NH}_{2}^{+}$ & $7.4^{o}$ & & & & & \\
\hline pyridine $^{+}$ & $-8.1^{n}$ & & & & & \\
\hline $\mathrm{F}^{-}$ & $-20.9 p$ & -13.5 & -8.1 & -5.7 & -4.3 & -3.5 \\
\hline
\end{tabular}




$\begin{array}{lccllll}\mathrm{Cl}^{-} & -9.0^{h} & -6.6 & -4.9 & -3.6 & -3.0 & -2.3 \\ \mathrm{Br}^{-} & -7.1^{h} & -5.6 & -4.4 & -3.1 & -2.3 & -1.9 \\ \mathrm{I}^{-} & -5.3 & -4.0 & -3.1 & -2.2 & -1.6 & \\ \mathrm{OH}^{-} & -19.8^{h} & -11.4^{e, q} & -8.4^{e, q} & -5.6^{e, q} & -4.3^{e, q} & -4.3^{e} \\ \mathrm{O}_{2}^{-} & -12.1^{h} & -9.7^{r} & -7.0^{r} & & \\ \mathrm{HS}^{-} & -8.6^{h} & -6.5^{s} & -4.7^{s} & & \\ \mathrm{HC}_{2}{ }^{-} & -10.6^{h} & & & & \\ \mathrm{CN}^{-} & -8.3^{h} & -6.3^{s} & -4.8^{s} & & \\ \mathrm{CH}_{3} \mathrm{O}^{-} & -17.0^{h} & -11.7^{t} & -7.5^{t} & -5.0^{t} & \\ \mathrm{HCO}_{2} & -9.1^{u} & & & & \\ \mathrm{CH}_{3} \mathrm{CO}_{2}^{-} & -9.3^{u} & & & & \\ \mathrm{C}_{6} \mathrm{H}_{5} \mathrm{O}^{-} & -8.2^{u} & & & & \\ \mathrm{CH}_{3} \mathrm{~S}^{-} & -8.7^{v} & -6.5^{v} & -5.0^{v} & -3.9^{v} & \\ \mathrm{C}_{6} \mathrm{H}_{5} \mathrm{~S}^{-} & -5.6^{v} & & & & \end{array}$




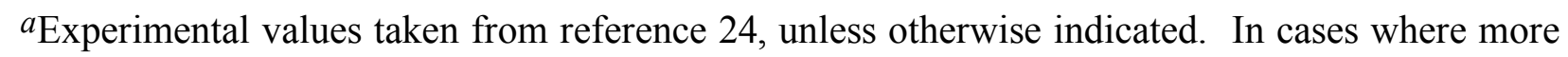
than a single reference is given for a single entry, the average value was used. ${ }^{b}$ Gas-phase free energy change for the reaction $\left(\mathrm{H}_{2} \mathrm{O}\right)_{i-1} \mathrm{M}^{ \pm}+\mathrm{H}_{2} \mathrm{O} \rightarrow\left(\mathrm{H}_{2} \mathrm{O}\right)_{i} \mathrm{M}^{ \pm}$for a standard-state gas-phase pressure of $1 \mathrm{~atm}$ and a temperature of $298 \mathrm{~K}$. ${ }^{c}$ Dzidic, I.; Kebarle, P. J. Phys. Chem. 1970, 74, 1466. ${ }^{d}$ Holland, P. M.; Castleman, A. W. J. Chem. Phys. 1982, 76, 4195. eMeot-Ner (Mautner), M.; Speller, C. V. J. Phys. Chem. 1986, 90, 6616. fCunningham, A. J.; Payzant, J. D.; Kebarle, P. J. Am. Chem. Soc. 1972, 94, 7627. gLau, Y. K.; Ikuta, S.; Kebarle, P. J. Am. Chem. Soc. 1982, 104, 1462. ${ }^{h}$ Reference ${ }^{14}$. ${ }^{i}$ Meot-Ner (Mautner), M. J. Am. Chem. Soc. 1984, 106, 1265. jKebarle, P. Annu. Rev. Phys. Chem. 1977, 28, 455. kPayzant, J. D.; Cunningham, A. J.; Kebarle, P. Can. J. Chem. 1973, 12, 403. 'Banic, C. M.; Iribarne, J. V. J. Chem. Phys. 1985, 83, 6432. ${ }^{m}$ Lau, Y. K.; Kebarle, P. Can. J. Chem. 1981, 59, 151. "nMeot-Ner (Mautner), M. J. Am. Chem. Soc. 1983, 105, 2956. ${ }^{o}$ Hiraoka, K.; Takimoto, H.; Yamabe, S. J. Am. Chem. Soc. 1987, 109, 7346. $p$ Weis, P.; Kemper, P. R.; Bowers, M. T.; Xantheas, S. J. Am. Chem. Soc. 1999, 121, 3531. qPayzant, J. D.;

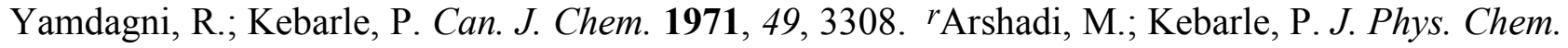
1970, 74, 1483. ${ }^{s}$ Meot-Ner (Mautner), M. J. Am. Chem. Soc. 1988, 110, 3854. ${ }^{t}$ Meot-Ner

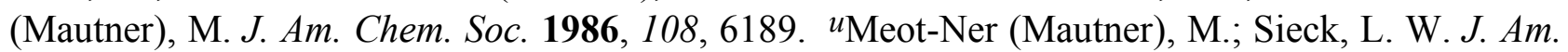
Chem. Soc. 1986, 108, 7525. v'Sieck, L. W.; Meot-Ner (Mautner), M. J. Phys. Chem. 1989, 93, 1586. 
TABLE 5: Conventional Aqueous Solvation Free Energies of Ion-Water Clusters (kcal/mol) ${ }^{a}$

\begin{tabular}{|c|c|c|c|c|c|c|}
\hline \multirow[b]{2}{*}{$M^{ \pm}$} & \multicolumn{6}{|c|}{$\Delta G_{\mathrm{S}}^{*, \operatorname{con}}\left[\left(\mathrm{H}_{2} \mathrm{O}\right)_{n} \mathrm{M}^{ \pm}\right]$} \\
\hline & $n=1$ & $n=2$ & $n=3$ & $n=4$ & $n=5$ & $n=6$ \\
\hline $\mathrm{Li}^{+}$ & 160.3 & 174.8 & 183.6 & 186.7 & 186.8 & 184.9 \\
\hline $\mathrm{Na}^{+}$ & 177.1 & 185.9 & 190.4 & 191.9 & 191.1 & 189.6 \\
\hline $\mathrm{K}^{+}$ & 187.3 & 191.8 & 193.6 & 193.6 & 192.4 & 190.3 \\
\hline $\mathrm{Rb}^{+}$ & 190.7 & 193.3 & 193.8 & 193.2 & 191.6 & \\
\hline $\mathrm{Cs}^{+}$ & 194.3 & 195.8 & 195.4 & 194.0 & & \\
\hline $\mathrm{Ag}^{+}$ & 167.6 & 182.0 & 186.1 & 187.8 & 188.1 & 187.4 \\
\hline $\mathrm{H}_{3} \mathrm{O}^{+}$ & 175.7 & 184.2 & 189.2 & 190.5 & 190.5 & 189.0 \\
\hline $\mathrm{CH}_{3} \mathrm{OH}_{2}^{+}$ & 186.9 & 194.9 & 197.6 & 198.2 & 197.4 & 195.7 \\
\hline $\mathrm{CH}_{3} \mathrm{CH}_{2} \mathrm{OH}_{2}^{+}$ & 189.9 & 196.3 & 198.4 & 198.8 & & \\
\hline$\left(\mathrm{CH}_{3}\right)_{2} \mathrm{OH}^{+}$ & 197.2 & & & & & \\
\hline $\mathrm{CH}_{3} \mathrm{C}(\mathrm{OH}) \mathrm{CH}_{3}^{+}$ & 197.2 & 199.5 & 201.3 & 201.2 & 200.0 & \\
\hline $\mathrm{CH}_{3} \mathrm{COHC}_{6} \mathrm{H}_{5}{ }^{+}$ & 207.8 & & & & & \\
\hline $\mathrm{NH}_{4}^{+}$ & 188.9 & 193.1 & 194.9 & 194.8 & 193.1 & \\
\hline $\mathrm{CH}_{3} \mathrm{NH}_{3}^{+}$ & 195.7 & 198.5 & 199.1 & 198.4 & & \\
\hline $\mathrm{CH}_{3}\left(\mathrm{CH}_{2}\right)_{2} \mathrm{NH}_{3}^{+}$ & 198.7 & 199.6 & 198.6 & 196.7 & & \\
\hline$\left(\mathrm{CH}_{3}\right)_{2} \mathrm{NH}_{2}^{+}$ & 201.6 & 203.4 & 203.1 & 201.6 & 199.3 & \\
\hline$\left(\mathrm{CH}_{3}\right)_{3} \mathrm{NH}^{+}$ & 207.9 & 207.7 & 206.3 & & & \\
\hline$\left(\mathrm{C}_{2} \mathrm{H}_{5}\right)_{3} \mathrm{NH}^{+}$ & 211.9 & & & & & \\
\hline$\left(n-\mathrm{C}_{3} \mathrm{H}_{7}\right)_{3} \mathrm{NH}^{+}$ & 214.1 & & & & & \\
\hline $\mathrm{C}_{4} \mathrm{H}_{8} \mathrm{NH}_{2}^{+}$ & 202.8 & & & & & \\
\hline pyridine $\mathrm{H}^{+}$ & 208.5 & & & & & \\
\hline $\mathrm{F}^{-}$ & -353.8 & -344.7 & -341.1 & -339.8 & -339.9 & -340.8 \\
\hline
\end{tabular}




$\begin{array}{lllllll}\mathrm{Cl}^{-} & -335.8 & -333.6 & -333.2 & -334.0 & -335.4 & -337.5 \\ \mathrm{Br}^{-} & -331.5 & -330.3 & -330.4 & -331.7 & -333.8 & -336.3 \\ \mathrm{I}^{-} & -324.9 & -325.3 & -326.7 & -328.9 & -331.7 & \\ \mathrm{OH}^{-} & -355.2 & -348.2 & -344.2 & -343.0 & -343.2 & -343.3 \\ \mathrm{O}_{2}^{-} & -341.5 & -336.2 & -333.7 & & & \\ \mathrm{HS}^{-} & -333.8 & -331.7 & -331.5 & & \\ \mathrm{HC}_{2}^{-} & -336.2 & & & & \\ \mathrm{CN}^{-} & -332.3 & -330.4 & -330.0 & & \\ \mathrm{CH}_{3} \mathrm{O}^{-} & -348.4 & -341.1 & -338.0 & -337.4 & \\ \mathrm{HCO}_{2}^{-} & -337.4 & & & & \\ \mathrm{CH}_{3} \mathrm{CO}_{2}^{-} & -338.6 & & & & \\ \mathrm{C}_{6} \mathrm{H}_{5} \mathrm{O}^{-} & -334.1 & & & & \\ \mathrm{CH}_{3} \mathrm{~S}^{-} & -335.5 & -333.4 & -332.8 & -333.3 & \\ \mathrm{C}_{6} \mathrm{H}_{5} \mathrm{~S}^{-} & -328.1 & & & \end{array}$

${ }^{a}$ All conventional solvation free energies are for a temperature of $298 \mathrm{~K}$, and use a standardstate concentration of $1 \mathrm{~mol} / \mathrm{L}$ in both the gas and the aqueous phases. 
TABLE 6: Conventional Aqueous Solvation Free Energies of Monohydrated Ions, Obtained Using Calculated Values for the Gas-

Phase Clustering Free Energy (kcal/mol) ${ }^{a}$

\begin{tabular}{lcc}
\hline \multicolumn{1}{c}{$\mathrm{M}^{ \pm}$} & $\Delta G_{0,1}^{\circ}\left(\mathrm{M}^{ \pm}\right)^{b}$ & $\Delta G_{\mathrm{S}}^{*, \mathrm{con}}\left[\left(\mathrm{H}_{2} \mathrm{O}\right) \mathrm{M}^{ \pm}\right]^{c}$ \\
\hline$\left(\mathrm{C}_{2} \mathrm{H}_{5}\right)_{2} \mathrm{OH}^{+}$ & -11.4 & 201.3 \\
$\mathrm{HO}_{2}{ }^{-}$ & -17.0 & -350.6 \\
$\mathrm{C}_{2} \mathrm{H}_{5} \mathrm{O}^{-}$ & -14.2 & -346.8 \\
$\mathrm{CH}_{3} \mathrm{CH}_{2} \mathrm{CH}_{2} \mathrm{O}^{-}$ & -14.6 & -344.1 \\
$\left(\mathrm{CH}_{3}\right)_{2} \mathrm{CHO}^{-}$ & -12.3 & -344.3 \\
$\mathrm{CH}_{3} \mathrm{CH}_{2} \mathrm{CHOCH}_{3}^{-}$ & -9.9 & -344.6 \\
${\mathrm{C}\left(\mathrm{CH}_{3}\right)_{3} \mathrm{O}^{-}}_{\mathrm{H}_{2} \mathrm{C}^{-} \mathrm{CHCH}_{2} \mathrm{O}^{-}}$ & -12.2 & -340.4 \\
$\mathrm{CH}_{3} \mathrm{OCH}_{2} \mathrm{CH}_{2} \mathrm{O}^{-}$ & -13.5 & -343.4 \\
$\mathrm{HOCH}_{2} \mathrm{CH}_{2} \mathrm{O}^{-}$ & -13.5 & -346.2 \\
$\mathrm{C}_{6} \mathrm{H}_{5} \mathrm{CH}_{2} \mathrm{O}^{-}$ & -14.0 & -341.6 \\
$\mathrm{CF}_{3} \mathrm{CH}_{2} \mathrm{O}^{-}$ & -11.6 & -343.7 \\
$\mathrm{CH}_{\left(\mathrm{CF}_{3}\right)_{2} \mathrm{O}^{-}}$ & -11.6 & -336.3 \\
$\mathrm{CH}_{3} \mathrm{OO}^{-}$ & -6.0 & -329.9 \\
$\mathrm{CH}_{3} \mathrm{CH}_{2} \mathrm{OO}^{-}$ & -14.6 & -348.9 \\
$\mathrm{All}_{2}$ & -14.1 & -345.4
\end{tabular}

${ }^{a}$ All data are for a temperature of $298 \mathrm{~K} .{ }^{b}$ Calculated (B97-1/MG3S) gas-phase free energy change for the reaction $\mathrm{M}^{ \pm}+\mathrm{H}_{2} \mathrm{O} \rightarrow\left(\mathrm{H}_{2} \mathrm{O}\right) \mathrm{M}^{ \pm}$for a standard-state gas-phase pressure of $1 \mathrm{~atm} .{ }^{c}$ Conventional solvation free energy of the monohydrated ion, for a standard-state concentration of 1 $\mathrm{mol} / \mathrm{L}$ in both the gas and the aqueous phases. 
TABLE 7: Absolute Aqueous Solvation Free Energy of the Proton (kcal/mol), Obtained Using Different Data Sets

\begin{tabular}{|c|c|c|c|c|}
\hline data set & no. $\operatorname{data}^{a}$ & $n^{b}$ & $\Delta G_{\mathrm{S}}^{*}\left(\mathrm{H}^{+}\right)^{c}$ & $\sigma^{d}$ \\
\hline all ions & 1109 & 6 & -266.1 & 0.71 \\
\hline all ions & 637 & 1 & -268.4 & \\
\hline all ions $e$ & 150 & 1 & -266.6 & \\
\hline monatomic cations & 377 & 6 & -265.1 & 0.77 \\
\hline oxonium ions & 334 & 6 & -267.8 & 1.15 \\
\hline ammonium ions & 398 & 5 & -265.8 & 0.86 \\
\hline monatomic cations & 174 & 1 & -264.4 & \\
\hline oxonium ions & 203 & 1 & -271.3 & \\
\hline ammonium ions & 260 & 1 & -267.7 & \\
\hline monatomic cations ${ }^{e}$ & 60 & 1 & -263.7 & \\
\hline oxonium ions $e^{e}$ & 40 & 1 & -269.3 & \\
\hline ammonium ions ${ }^{e}$ & 50 & 1 & -266.8 & \\
\hline all ions $f$ & 787 & 6 & -266.1 & 0.70 \\
\hline all ions $f$ & 315 & 1 & -268.0 & \\
\hline Tisandier et al. $g$ & 109 & 6 & -265.6 & 0.71 \\
\hline Tissandier et al. $g$ & 20 & 1 & -265.1 & \\
\hline Tissandier et al. ${ }^{h}$ & 109 & 6 & -265.9 & 0.07 \\
\hline
\end{tabular}

${ }^{a}$ Total number of differential conventional aqueous solvation free energies used to determine the $\Delta G_{\mathrm{S}}^{*}\left(\mathrm{H}^{+}\right)$and $\sigma$ values. ${ }^{b}$ Maximum number of clustering water molecules used to determine the $\Delta G_{\mathrm{S}}^{*}\left(\mathrm{H}^{+}\right)$and $\sigma$ values. ${ }^{c}$ Standard-state absolute aqueous solvation free energy of the proton. $d$ Standard deviation of the $n(n+1) / 2$ determinations of $\Delta G_{\mathrm{S}}^{*}\left(\mathrm{H}^{+}\right)(\mathrm{kcal} / \mathrm{mol})$ from the average $\Delta G_{\mathrm{S}}^{*}\left(\mathrm{H}^{+}\right)$value. ${ }^{e}$ Ions for which gas-phase clusering data are not available for $n>1$ were not used to determine the $\Delta G_{\mathrm{S}}^{*}\left(\mathrm{H}^{+}\right)$and $\sigma$ values. $f_{\text {Only ions for which experimental gas- }}$ phase clustering free energies are available were used to determine the $\Delta G_{\mathrm{S}}^{*}\left(\mathrm{H}^{+}\right)$ and $\sigma$ values. gConventional aqueous solvation free energies and gas-phase binding free energies taken from ref 24 were used to determine the $\Delta G_{\mathrm{S}}^{*}\left(\mathrm{H}^{+}\right)$and $\sigma$ values. $h$ The values were taken from ref 24 . 
TABLE 8: Absolute Aqueous Solvation Free Energies of Unclustered Ions (kcal/mol) ${ }^{a}$

\begin{tabular}{|c|c|c|c|c|c|c|c|}
\hline $\mathrm{M}^{+}$ & ref 14 & ref 23 & this work & $\mathrm{M}^{-}$ & ref 14 & ref 23 & this work \\
\hline $\mathrm{Li}^{+}$ & & & -128.4 & $\mathrm{Cl}^{-}$ & -73.0 & -74.6 & -74.5 \\
\hline $\mathrm{K}^{+}$ & & & -86.0 & $\mathrm{I}^{-}$ & & -59.9 & -59.9 \\
\hline $\mathrm{Rb}^{+}$ & & & -80.6 & $\mathrm{OH}^{-}$ & -106.3 & -105.0 & -104.7 \\
\hline $\mathrm{Cu}^{+}$ & & & -141.3 & $\mathrm{HS}^{-}$ & -73.7 & -71.6 & -72.1 \\
\hline $\mathrm{Ag}^{+}$ & & & -118.7 & $\mathrm{HC}_{2}^{-}$ & -78.1 & -76.1 & -76.5 \\
\hline $\mathrm{H}_{3} \mathrm{O}^{+}$ & -108.7 & -110.2 & -110.3 & $\mathrm{CN}^{-}$ & -71.8 & -67.6 & -70.2 \\
\hline $\mathrm{CH}_{3} \mathrm{OH}_{2}^{+}$ & -91.4 & -93.1 & -93.0 & $\mathrm{CH}_{3} \mathrm{O}^{-}$ & -96.6 & -95.2 & -95.0 \\
\hline $\mathrm{CH}_{3} \mathrm{C}(\mathrm{OH}) \mathrm{CH}_{3}{ }^{+}$ & -75.5 & -76.8 & -77.1 & $\mathrm{CH}_{3} \mathrm{CH}_{2} \mathrm{CHOCH}_{3}^{-}$ & -85.8 & & -84.2 \\
\hline $\mathrm{CH}_{3} \mathrm{C}(\mathrm{OH}) \mathrm{C}_{6} \mathrm{H}_{5}^{+}$ & -62.9 & -65.1 & -64.5 & $\mathrm{C}\left(\mathrm{CH}_{3}\right)_{3} \mathrm{O}^{-}$ & -83.9 & & -82.3 \\
\hline $\mathrm{NH}_{4}^{+}$ & -83.6 & -85.2 & -85.2 & $\mathrm{H}_{2} \mathrm{C}=\mathrm{CHCH}_{2} \mathrm{O}^{-}$ & -88.2 & & -86.6 \\
\hline $\mathrm{CH}_{3} \mathrm{NH}_{3}^{+}$ & -74.8 & -76.5 & -76.4 & $\mathrm{CH}_{3} \mathrm{OCH}_{2} \mathrm{CH}_{2} \mathrm{O}^{-}$ & -91.0 & & -89.4 \\
\hline $\mathrm{CH}_{3}\left(\mathrm{CH}_{2}\right)_{2} \mathrm{NH}_{3}^{+}$ & -69.9 & -71.5 & -71.5 & $\mathrm{HOCH}_{2} \mathrm{CH}_{2} \mathrm{O}^{-}$ & -86.9 & & -85.3 \\
\hline$\left(\mathrm{CH}_{3}\right)_{2} \mathrm{CHNH}_{3}^{+}$ & -68.0 & & -69.6 & $\mathrm{C}_{6} \mathrm{H}_{5} \mathrm{CH}_{2} \mathrm{O}^{-}$ & -86.7 & & -85.1 \\
\hline $\mathrm{C}\left(\mathrm{CH}_{3}\right)_{3} \mathrm{NH}_{3}^{+}$ & -65.7 & & -67.3 & $\mathrm{CF}_{3} \mathrm{CH}_{2} \mathrm{O}^{-}$ & -79.1 & & -77.5 \\
\hline$c-\mathrm{C}_{6} \mathrm{H}_{11} \mathrm{NH}_{3}^{+}$ & -67.1 & & -68.7 & $\mathrm{CH}\left(\mathrm{CF}_{3}\right)_{2} \mathrm{O}^{-}$ & -67.1 & & -65.5 \\
\hline
\end{tabular}




\begin{tabular}{|c|c|c|c|c|c|c|c|}
\hline$\left(\mathrm{CH}_{3}\right)_{2} \mathrm{NH}_{2}^{+}$ & -67.0 & -68.6 & -68.6 & $\mathrm{CH}_{3} \mathrm{CH}_{2} \mathrm{OO}^{-}$ & -90.8 & & -89.2 \\
\hline$\left(\mathrm{C}_{2} \mathrm{H}_{5}\right)_{2} \mathrm{NH}_{2}^{+}$ & -61.8 & -63.2 & -63.4 & $\mathrm{HCO}_{2}^{-}$ & -77.8 & -76.2 & -76.2 \\
\hline$\left(n-\mathrm{C}_{3} \mathrm{H}_{7}\right)_{2} \mathrm{NH}_{2}^{+}$ & -58.9 & & -60.5 & $\mathrm{CH}_{3} \mathrm{CO}_{2}^{-}$ & -79.2 & -77.3 & -77.6 \\
\hline$\left(\mathrm{H}_{2} \mathrm{C}=\mathrm{CHCH}_{2}\right)_{2} \mathrm{NH}_{2}^{+}$ & -60.0 & & -61.6 & $\mathrm{CH}_{3} \mathrm{CH}_{2} \mathrm{CO}_{2}^{-}$ & -77.8 & & -76.2 \\
\hline$\left(\mathrm{CH}_{3}\right)_{3} \mathrm{NH}^{+}$ & -59.5 & -61.2 & -61.1 & $\mathrm{CH}_{3}\left(\mathrm{CH}_{2}\right)_{4} \mathrm{CO}_{2}^{-}$ & -76.2 & & -74.6 \\
\hline$\left(\mathrm{C}_{2} \mathrm{H}_{5}\right)_{3} \mathrm{NH}^{+}$ & -53.0 & -54.7 & -54.6 & $\mathrm{H}_{2} \mathrm{C}=\mathrm{CHCO}_{2}^{-}$ & -75.6 & & -74.0 \\
\hline$\left(n-\mathrm{C}_{3} \mathrm{H}_{7}\right)_{3} \mathrm{NH}^{+}$ & -49.3 & & -50.9 & $\mathrm{CH}_{3} \mathrm{COCO}_{2}^{-}$ & -70.1 & & -68.5 \\
\hline $\mathrm{C}_{6} \mathrm{H}_{5} \mathrm{NH}_{3}^{+}$ & -70.8 & -72.8 & -72.4 & $\mathrm{CH}_{2} \mathrm{ClCO}_{2}^{-}$ & -71.3 & & -69.7 \\
\hline$o-\mathrm{CH}_{3} \mathrm{C}_{6} \mathrm{H}_{4} \mathrm{NH}_{3}^{+}$ & -68.7 & & -70.3 & $\mathrm{CHCl}_{2} \mathrm{CO}_{2}^{-}$ & -63.9 & & -62.3 \\
\hline$m-\mathrm{CH}_{3} \mathrm{C}_{6} \mathrm{H}_{4} \mathrm{NH}_{3}^{+}$ & -68.0 & & -69.6 & $\mathrm{CF}_{3} \mathrm{CO}_{2}^{-}$ & -60.9 & & -59.3 \\
\hline$p-\mathrm{CH}_{3} \mathrm{C}_{6} \mathrm{H}_{4} \mathrm{NH}_{3}^{+}$ & -68.2 & & -69.8 & $\mathrm{C}_{6} \mathrm{H}_{5} \mathrm{CO}_{2}^{-}$ & -72.8 & -71.2 & -71.2 \\
\hline$m-\mathrm{NH}_{2} \mathrm{C}_{6} \mathrm{H}_{4} \mathrm{NH}_{3}^{+}$ & -64.2 & & -65.8 & $\mathrm{C}_{6} \mathrm{H}_{5} \mathrm{O}^{-}$ & -73.5 & -71.3 & -71.9 \\
\hline $\mathrm{C}_{6} \mathrm{H}_{5} \mathrm{NH}_{2} \mathrm{CH}_{3}^{+}$ & -61.0 & & -62.6 & $o-\mathrm{CH}_{3} \mathrm{C}_{6} \mathrm{H}_{4} \mathrm{O}^{-}$ & -71.8 & & -70.2 \\
\hline $\mathrm{C}_{6} \mathrm{H}_{5} \mathrm{NH}_{2} \mathrm{CH}_{2} \mathrm{CH}_{3}{ }^{+}$ & -60.6 & & -62.2 & $m-\mathrm{CH}_{3} \mathrm{C}_{6} \mathrm{H}_{4} \mathrm{O}^{-}$ & -72.7 & & -71.1 \\
\hline $\mathrm{C}_{6} \mathrm{H}_{5} \mathrm{NH}\left(\mathrm{CH}_{3}\right)_{2}^{+}$ & -55.6 & & -57.2 & $p-\mathrm{CH}_{3} \mathrm{C}_{6} \mathrm{H}_{4} \mathrm{O}^{-}$ & -73.6 & & -72.0 \\
\hline$p-\mathrm{CH}_{3} \mathrm{C}_{6} \mathrm{H}_{4} \mathrm{NH}\left(\mathrm{CH}_{3}\right)_{2}{ }^{+}$ & -54.3 & & -55.9 & $m-\mathrm{HOC}_{6} \mathrm{H}_{4} \mathrm{O}^{-}$ & -75.4 & & -73.8 \\
\hline $\mathrm{C}_{6} \mathrm{H}_{5} \mathrm{NH}\left(\mathrm{CH}_{2} \mathrm{CH} 3\right)_{2}^{+}$ & -52.4 & & -54.0 & $p-\mathrm{HOC}_{6} \mathrm{H}_{4} \mathrm{O}^{-}$ & -79.2 & & -77.6 \\
\hline $\mathrm{C}_{10} \mathrm{H}_{7} \mathrm{NH}_{3}^{+}$ & -65.8 & & -67.4 & $o-\mathrm{NO}_{2} \mathrm{C}_{6} \mathrm{H}_{4} \mathrm{O}^{-}$ & -61.7 & & -60.1 \\
\hline $\mathrm{C}_{2} \mathrm{H}_{4} \mathrm{NH}_{2}^{+}$ & -69.3 & & -70.9 & $m-\mathrm{NO}_{2} \mathrm{C}_{6} \mathrm{H}_{4} \mathrm{O}^{-}$ & -63.5 & & -61.9 \\
\hline $\mathrm{C}_{3} \mathrm{H}_{6} \mathrm{NH}_{2}^{+}$ & -66.1 & & -67.7 & $p-\mathrm{NO}_{2} \mathrm{C}_{6} \mathrm{H}_{4} \mathrm{O}^{-}$ & -59.4 & & -57.8 \\
\hline $\mathrm{C}_{4} \mathrm{H}_{8} \mathrm{NH}_{2}^{+}$ & -64.4 & & -66.0 & $o-\mathrm{ClC}_{6} \mathrm{H}_{4} \mathrm{O}^{-}$ & -67.7 & & -66.1 \\
\hline $\mathrm{C}_{5} \mathrm{H}_{10} \mathrm{NH}_{2}^{+}$ & -62.6 & & -64.2 & $p-\mathrm{ClC}_{6} \mathrm{H}_{4} \mathrm{O}^{-}$ & -67.6 & & -66.0 \\
\hline $\mathrm{C}_{6} \mathrm{H}_{12} \mathrm{NH}_{2}^{+}$ & -61.7 & & -63.3 & $\mathrm{CH}_{2}(\mathrm{O}) \mathrm{CH}^{-}$ & -78.1 & -75.7 & -76.5 \\
\hline $\mathrm{C}_{4} \mathrm{H}_{5} \mathrm{NH}^{+}$ & -59.8 & & -61.4 & $\mathrm{CH}_{3} \mathrm{C}(\mathrm{O}) \mathrm{CH}_{2}^{-}$ & -77.8 & -75.6 & -76.2 \\
\hline Pyridine $^{+}$ & -59.5 & -61.1 & -61.1 & $\mathrm{CH}_{3} \mathrm{CH}_{2} \mathrm{C}(\mathrm{O}) \mathrm{CHCH}_{3}^{-}$ & -75.3 & & -73.7 \\
\hline $\mathrm{C}_{9} \mathrm{H}_{7} \mathrm{NH}^{+}$ & -54.4 & & -56.0 & $\mathrm{NCNH}^{-}$ & -73.8 & & -72.2 \\
\hline
\end{tabular}




\begin{tabular}{|c|c|c|c|c|c|c|c|}
\hline $\mathrm{C}_{4} \mathrm{H}_{8} \mathrm{NHNH}_{2}^{+}$ & -64.4 & & -66.0 & $\mathrm{CH}_{2} \mathrm{CN}^{-}$ & -73.5 & -65.7 & -66.6 \\
\hline $\mathrm{CH}_{3} \mathrm{CNH}^{+}$ & -73.7 & & -75.3 & $\mathrm{C}_{6} \mathrm{H}_{5} \mathrm{NH}^{-}$ & -64.5 & -63.8 & -62.9 \\
\hline $\mathrm{H}_{2} \mathrm{NNH}_{3}^{+}$ & -83.0 & & -84.6 & $p-\mathrm{NO}_{2} \mathrm{C}_{6} \mathrm{H}_{5} \mathrm{NH}^{-}$ & -59.0 & & -57.4 \\
\hline$p-\mathrm{CH}_{3} \mathrm{OC}_{6} \mathrm{H}_{4} \mathrm{NH}_{3}{ }^{+}$ & -69.6 & & -71.2 & $\left(\mathrm{C}_{6} \mathrm{H}_{5}\right)_{2} \mathrm{~N}^{-}$ & -56.2 & & -54.6 \\
\hline$p-\mathrm{NO}_{2} \mathrm{C}_{6} \mathrm{H}_{4} \mathrm{NH}_{3}^{+}$ & -74.3 & & -75.9 & $\mathrm{CH}_{3} \mathrm{CONH}^{-}$ & -81.8 & -80.1 & -80.2 \\
\hline $\mathrm{C}_{4} \mathrm{H}_{8} \mathrm{ONH}_{2}^{+}$ & -68.0 & & -69.6 & $\mathrm{CH}_{2} \mathrm{NO}_{2}^{-}$ & -78.1 & -75.9 & -76.5 \\
\hline $\mathrm{CH}_{3} \mathrm{COHNH}_{2}^{+}$ & -72.3 & -73.8 & -73.9 & $\mathrm{CH}_{3} \mathrm{~S}^{-}$ & -75.4 & -73.7 & -73.8 \\
\hline $\mathrm{C}_{6} \mathrm{H}_{5} \mathrm{COHNH}_{2}^{+}$ & -65.6 & & -67.2 & $\mathrm{CH}_{3} \mathrm{CH}_{2} \mathrm{~S}^{-}$ & -73.4 & & -71.8 \\
\hline$\left(\mathrm{CH}_{3}\right)_{2} \mathrm{SH}^{+}$ & -62.9 & -64.5 & -64.5 & $\mathrm{C}_{3} \mathrm{H}_{7} \mathrm{~S}^{-}$ & -72.1 & & -70.5 \\
\hline$\left(\mathrm{CH}_{3}\right)_{2} \mathrm{SOH}^{+}$ & -66.1 & -68.2 & -67.7 & $\mathrm{C}_{6} \mathrm{H}_{5} \mathrm{~S}^{-}$ & -65.0 & -63.3 & -63.4 \\
\hline$m-\mathrm{ClC}_{6} \mathrm{H}_{4} \mathrm{NH}_{3}^{+}$ & -73.1 & & -74.7 & $\mathrm{CH}_{3} \mathrm{~S}(\mathrm{O}) \mathrm{CH}_{2}^{-}$ & -69.3 & & -67.7 \\
\hline$p-\mathrm{ClC}_{6} \mathrm{H}_{4} \mathrm{NH}_{3}{ }^{+}$ & -72.5 & & -74.1 & $\mathrm{CCl}_{3}^{-}$ & -55.7 & & -54.1 \\
\hline
\end{tabular}

${ }^{a}$ Solvation free energies are for a temperature of $298 \mathrm{~K}$ and use a standard-state concentration of $1 \mathrm{~mol} / \mathrm{L}$ in both the gas and the aqueous phases. Ions in this table are listed in the same order as in Tables 1-3. 
TABLE 9: Absolute Aqueous Solvation Free Energies (kcal/mol) of Clustered Ions ( $n=$ Number of Clustering Water Molecules) ${ }^{a}$

\begin{tabular}{|c|c|c|c|c|c|c|c|}
\hline \multirow{2}{*}{$\mathrm{M}^{ \pm}$} & \multicolumn{2}{|c|}{$n=1$} & \multirow[b]{2}{*}{$n=2$} & \multirow[b]{2}{*}{$n=3$} & \multirow[b]{2}{*}{$n=4$} & \multirow[b]{2}{*}{$n=5$} & \multirow[b]{2}{*}{$n=6$} \\
\hline & ref 14 & this work & & & & & \\
\hline $\mathrm{Li}^{+}$ & & -105.6 & -91.1 & -82.3 & -79.2 & -79.1 & -81.0 \\
\hline $\mathrm{Na}^{+}$ & & -88.8 & -80.0 & -75.5 & -74.0 & -74.8 & -76.3 \\
\hline $\mathrm{K}^{+}$ & & -78.6 & -74.1 & -72.3 & -72.3 & -73.5 & -75.6 \\
\hline $\mathrm{Rb}^{+}$ & & -75.2 & -72.6 & -72.1 & -72.7 & -74.3 & \\
\hline $\mathrm{Cs}^{+}$ & & -71.6 & -70.1 & -70.5 & -71.9 & & \\
\hline $\mathrm{Ag}^{+}$ & & -98.3 & -83.9 & -79.8 & -78.1 & -77.8 & -78.5 \\
\hline $\mathrm{H}_{3} \mathrm{O}^{+}$ & -86.1 & -90.2 & -81.7 & -76.7 & -75.4 & -75.4 & -76.9 \\
\hline $\mathrm{CH}_{3} \mathrm{OH}_{2}^{+}$ & -77.4 & -79.0 & -71.0 & -68.3 & -67.7 & -68.5 & -70.2 \\
\hline $\mathrm{CH}_{3} \mathrm{CH}_{2} \mathrm{OH}_{2}^{+}$ & -74.4 & -76.0 & -69.6 & -67.5 & -67.1 & & \\
\hline$\left(\mathrm{CH}_{3}\right)_{2} \mathrm{OH}^{+}$ & -67.1 & -68.7 & & & & & \\
\hline$\left(\mathrm{C}_{2} \mathrm{H}_{5}\right)_{2} \mathrm{OH}^{+}$ & $-63.0^{b}$ & $-64.6^{b}$ & & & & & \\
\hline $\mathrm{CH}_{3} \mathrm{C}(\mathrm{OH}) \mathrm{CH}_{3}{ }^{+}$ & -67.1 & -68.7 & -66.4 & -64.6 & -64.7 & -65.9 & \\
\hline $\mathrm{CH}_{3} \mathrm{C}(\mathrm{OH}) \mathrm{C}_{6} \mathrm{H}_{5}^{+}$ & -56.5 & -58.1 & & & & & \\
\hline $\mathrm{NH}_{4}^{+}$ & -75.4 & -77.0 & -72.8 & -71.0 & -71.2 & -72.8 & \\
\hline $\mathrm{CH}_{3} \mathrm{NH}_{3}^{+}$ & & -70.2 & -67.4 & -66.8 & -67.5 & & \\
\hline $\mathrm{CH}_{3}\left(\mathrm{CH}_{2}\right)_{2} \mathrm{NH}_{3}^{+}$ & & -67.2 & -66.3 & -67.3 & -69.2 & & \\
\hline$\left(\mathrm{CH}_{3}\right)_{2} \mathrm{NH}_{2}^{+}$ & & -64.3 & -62.5 & -62.8 & -64.3 & -66.6 & \\
\hline$\left(\mathrm{CH}_{3}\right)_{3} \mathrm{NH}^{+}$ & & -58.0 & -58.2 & -59.7 & & & \\
\hline$\left(\mathrm{C}_{2} \mathrm{H}_{5}\right)_{3} \mathrm{NH}^{+}$ & & -54.0 & & & & & \\
\hline$\left(n-\mathrm{C}_{3} \mathrm{H}_{7}\right)_{3} \mathrm{NH}^{+}$ & & -51.8 & & & & & \\
\hline $\mathrm{C}_{4} \mathrm{H}_{8} \mathrm{NH}_{2}^{+}$ & & -63.1 & & & & & \\
\hline pyridine $^{+}$ & & -57.4 & & & & & \\
\hline $\mathrm{F}^{-}$ & -94.4 & -87.9 & -78.8 & -75.2 & -73.9 & -74.0 & -74.9 \\
\hline $\mathrm{Cl}^{-}$ & -68.4 & -69.9 & -67.7 & -67.3 & -68.1 & -69.5 & -71.6 \\
\hline $\mathrm{Br}^{-}$ & -63.9 & -65.6 & -64.4 & -64.5 & -65.8 & -67.9 & -70.4 \\
\hline $\mathrm{I}^{-}$ & & -59.0 & -59.4 & -60.8 & -63.0 & -65.8 & \\
\hline $\mathrm{OH}^{-}$ & -90.9 & -89.3 & -82.3 & -78.3 & -77.1 & -77.3 & -77.4 \\
\hline $\mathrm{HO}_{2}^{-}$ & $-86.3^{b, c}$ & $-84.7^{b, c}$ & & & & & \\
\hline $\mathrm{O}_{2}^{-}$ & -77.2 & -75.6 & -70.3 & -67.8 & & & \\
\hline $\mathrm{HS}^{-}$ & -69.5 & -67.9 & -65.8 & -65.6 & & & \\
\hline $\mathrm{HC}_{2}^{-}$ & -71.9 & -70.3 & & & & & \\
\hline $\mathrm{CN}^{-}$ & -68.0 & -66.4 & -64.5 & -64.1 & & & \\
\hline $\mathrm{CH}_{3} \mathrm{O}^{-}$ & -84.0 & -82.5 & -75.2 & -72.1 & -71.5 & & \\
\hline
\end{tabular}




$\begin{array}{lll}\mathrm{C}_{2} \mathrm{H}_{5} \mathrm{O}^{-} & -82.5^{b} & -80.9^{b} \\ \mathrm{CH}_{3} \mathrm{CH}_{2} \mathrm{CH}_{2} \mathrm{O}^{-} & -79.8^{b} & -78.2^{b} \\ \left(\mathrm{CH}_{3}\right)_{2} \mathrm{CHO}^{-} & -80.0^{b} & -78.4^{b} \\ \mathrm{CH}_{3} \mathrm{CH}_{2} \mathrm{CHOCH}_{3}^{-} & -80.3^{b} & -78.7^{b} \\ \mathrm{C}_{\left(\mathrm{CH}_{3}\right)_{3} \mathrm{O}^{-}} & -76.1^{b} & -74.5^{b} \\ \mathrm{H}_{2} \mathrm{C}=\mathrm{CHCH}_{2} \mathrm{O}^{-} & -79.1^{b} & -77.5^{b} \\ \mathrm{CH}_{3} \mathrm{OCH}_{2} \mathrm{CH}_{2} \mathrm{O}^{-} & -81.9^{b} & -80.3^{b} \\ \mathrm{HOCH}_{2} \mathrm{CH}_{2} \mathrm{O}^{-} & -77.2^{b} & -75.7^{b} \\ \mathrm{C}_{6} \mathrm{H}_{5} \mathrm{CH}_{2} \mathrm{O}^{-} & -79.4^{b} & -77.8^{b} \\ \mathrm{CF}_{3} \mathrm{CH}_{2} \mathrm{O}^{-} & -72.0^{b} & -70.4^{b} \\ \mathrm{CH}_{\left(\mathrm{CF}_{3}\right)_{2} \mathrm{O}^{-}} & -65.5^{b} & -64.0^{b} \\ \mathrm{CH}_{3} \mathrm{OO}^{-} & -84.6^{b} & -83.0^{b} \\ \mathrm{CH}_{3} \mathrm{CH}_{2} \mathrm{OO}^{-} & -81.0^{b} & -79.5^{b} \\ \mathrm{HCO}_{2}^{-} & -71.5 \\ \mathrm{CH}_{3} \mathrm{CO}_{2}^{-} & -72.7 \\ \mathrm{C}_{6} \mathrm{H}_{5} \mathrm{O}^{-} & & -68.2 \\ \mathrm{CH}_{3} \mathrm{~S}^{-} & & -69.6 \\ \mathrm{C}_{6} \mathrm{H}_{5} \mathrm{~S}^{-} & & -62.2\end{array}$

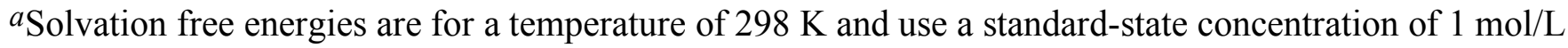
in both the gas and the aqueous phases. ${ }^{b}$ Calculated (B97-1/MG3S) clustering free energy used. ${ }^{c}$ Proton transfer from water to $\mathrm{HOO}^{-}$occurs without barrier in this cluster so that the resulting ion is better described as $\left(\mathrm{HO}^{-}\right)\left(\mathrm{H}_{2} \mathrm{O}_{2}\right)$ than $\left(\mathrm{HOO}^{-}\right)\left(\mathrm{H}_{2} \mathrm{O}\right)$. 
TABLE 10: Mean Unsigned Errors (kcal/mol) in Absolute Aqueous Solvation Free Energies of Ions ${ }^{a}$ and Ion-Water Clusters ${ }^{b}$ for Various Continuum Solvent Models, Computed Using Absolute Aqueous Solvation Free Energies Reported in Ref 14 and in This Work

\begin{tabular}{|c|c|c|c|c|}
\hline \multirow[b]{2}{*}{ solvent model } & \multicolumn{2}{|c|}{$\begin{array}{c}\text { selectively clustered } \\
\text { ion data } \operatorname{set}^{c} \\
\end{array}$} & \multicolumn{2}{|c|}{ all ions ${ }^{d}$} \\
\hline & ref. 14 & this work & ref. 14 & this work \\
\hline SM6/MPW25/MIDI! & 4.2 & 3.7 & 5.3 & 4.8 \\
\hline SM6/MPW25/6-31G(d) & 3.8 & 3.3 & 4.9 & 4.5 \\
\hline SM6/MPW25/6-31+G(d) & 3.3 & 3.5 & 4.5 & 4.6 \\
\hline SM6/MPW25/6-31+G(d,p) & 3.2 & 3.5 & 4.4 & 4.5 \\
\hline SM6/B3LYP/6-31+G(d,p) & 3.3 & 3.6 & 4.5 & 4.7 \\
\hline SM6/B3PW91/6-31+G(d,p) & 3.2 & 3.5 & 4.4 & 4.6 \\
\hline SM5.43R/MPW25/6-31+G(d,p) & 6.2 & 5.3 & 6.9 & 6.1 \\
\hline $\mathrm{DPCM} / 98 / \mathrm{HF} / 6-31 \mathrm{G}(\mathrm{d})^{e, f}$ & 5.9 & 5.8 & 5.8 & 5.7 \\
\hline $\mathrm{DPCM} / 03 / \mathrm{HF} / 6-31 \mathrm{G}(\mathrm{d})^{e, g}$ & 14.3 & 13.0 & 15.6 & 14.3 \\
\hline $\mathrm{CPCM} / 98 / \mathrm{HF} / 6-31 \mathrm{G}(\mathrm{d})^{e, f}$ & 6.3 & 6.0 & 6.4 & 6.0 \\
\hline $\mathrm{CPCM} / 03 / \mathrm{HF} / 6-31 \mathrm{G}(\mathrm{d})^{e, g}$ & 7.6 & 7.3 & 7.5 & 7.1 \\
\hline IEF-PCM/03/HF/6-31G(d) ${ }^{e, g}$ & 7.6 & 7.4 & 7.5 & 7.2 \\
\hline IEF-PCM/03/MPW25/6-31+G(d,p) ${ }^{e, g}$ & 9.0 & 8.6 & 8.9 & 8.4 \\
\hline \multicolumn{5}{|c|}{ 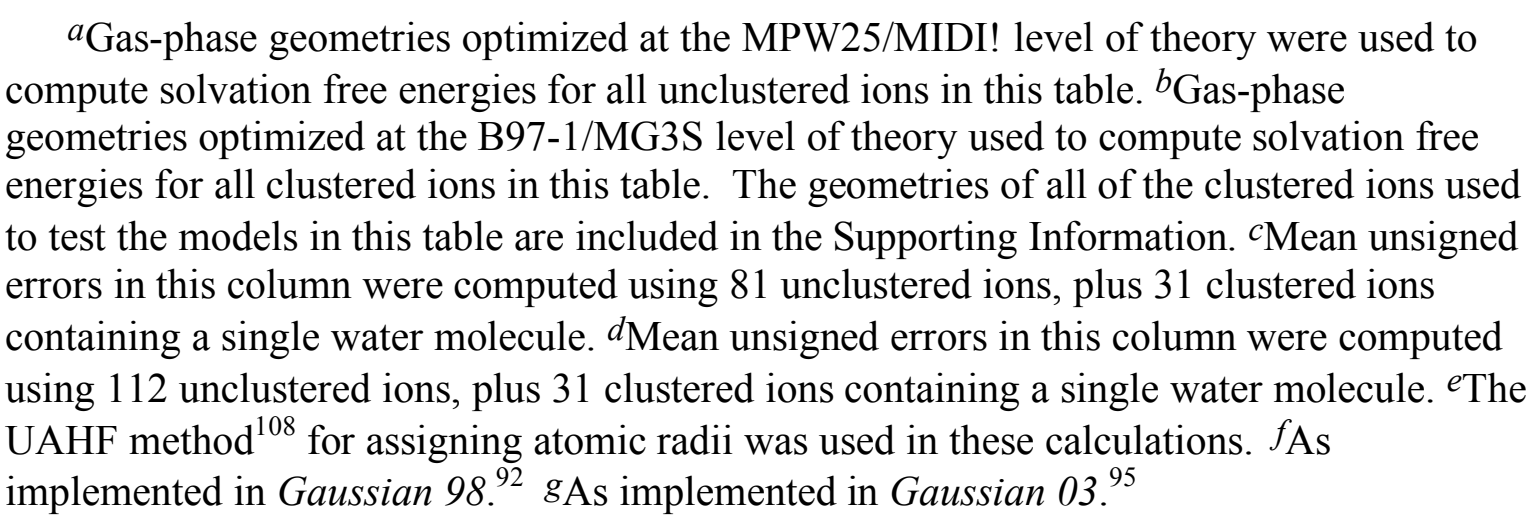 } \\
\hline
\end{tabular}


Figure captions

Figure 1. Half of the difference between conventional aqueous solvation free energies of anions and of cations for cluster ions containing up to six water molecules plotted vs half of the difference between conventional aqueous solvation free energies of anions and of cations containing no water molecules. Differences between cluster ions containing one water are plotted in gray, two waters in red, three waters in green, four waters in blue, five waters in orange, and six waters in brown. The ideal line (no clustering waters) is shown as a solid black line. The ordinate of each of the intersection points in the above plot is an approximate value for the absolute aqueous solvation free energy of the proton.

Figure 2. Half of the difference between conventional aqueous solvation free energies of anions and of cations ions for cluster ions containing a single water molecule plotted vs half of the difference between conventional aqueous solvation free energies of anions and of cations containing no water molecules. Differences between anions and monatomic cations are plotted in black, those between anions and oxonium cations in red, and those between ammonium cations and anions in blue. 


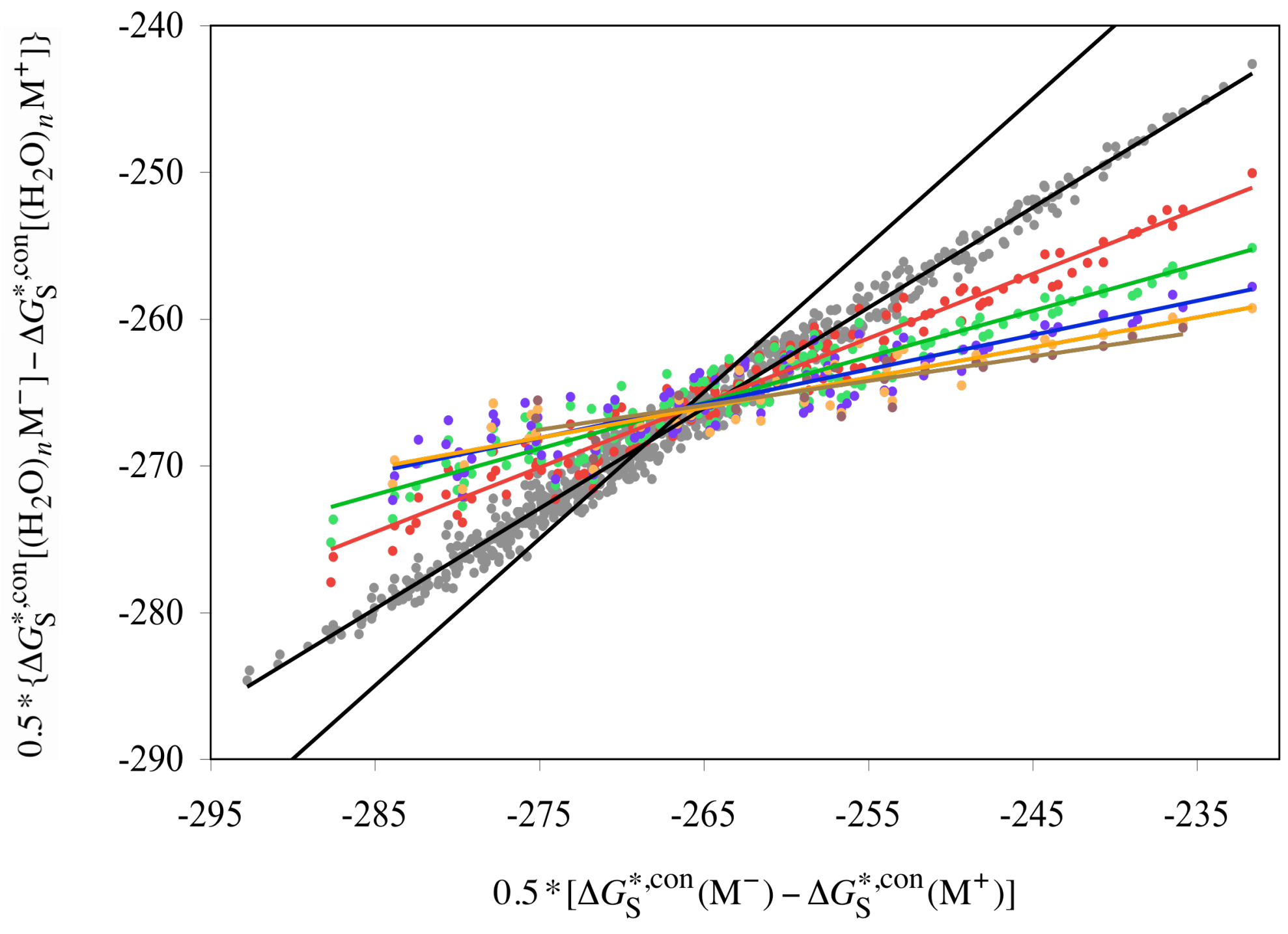




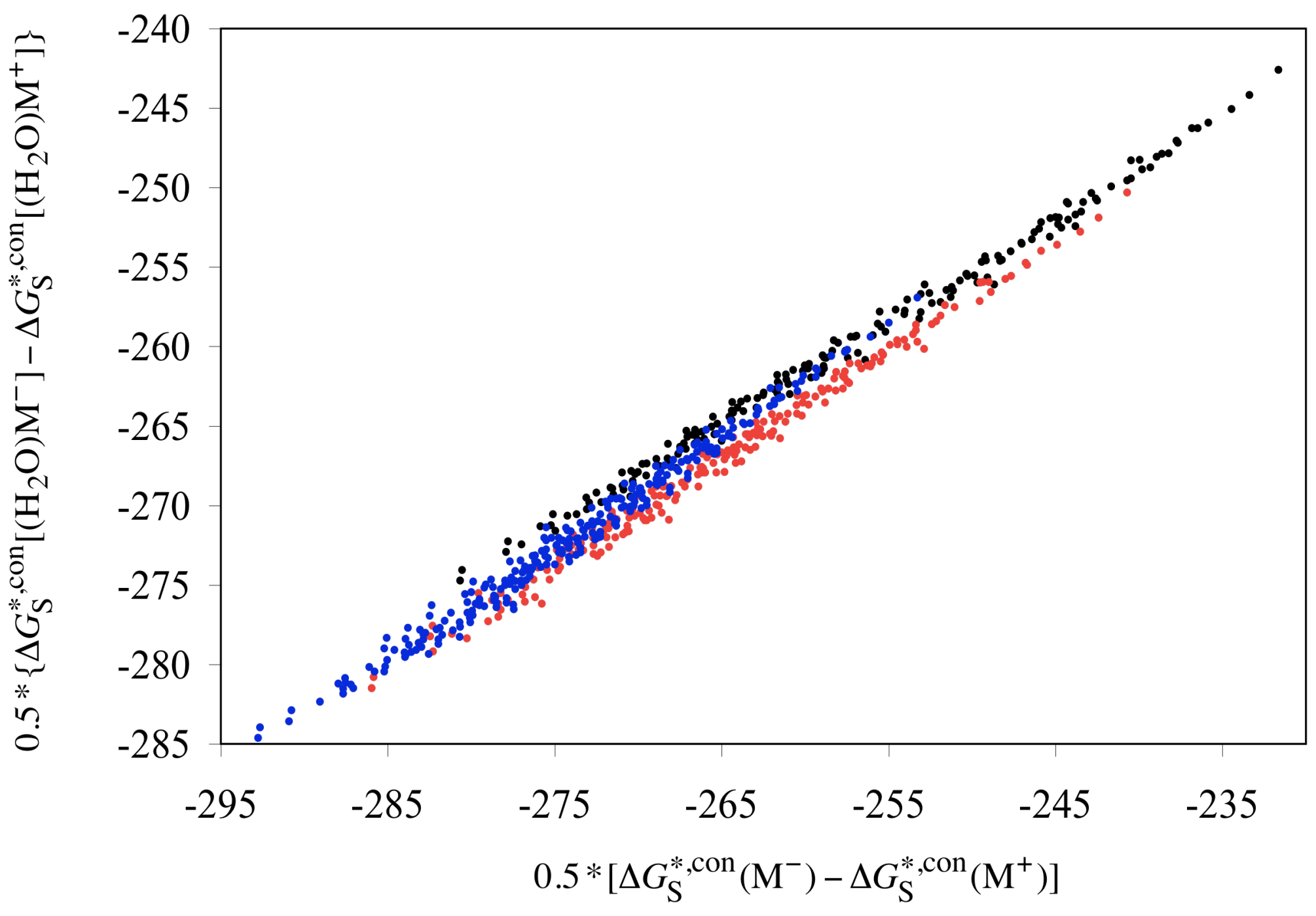




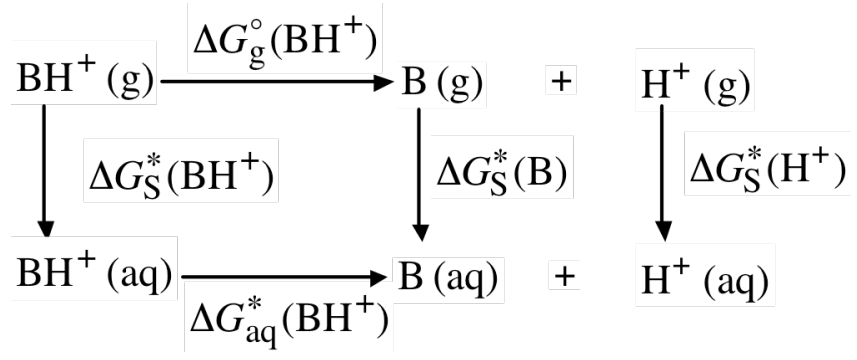

Scheme 1: Thermochemical Cycle 1

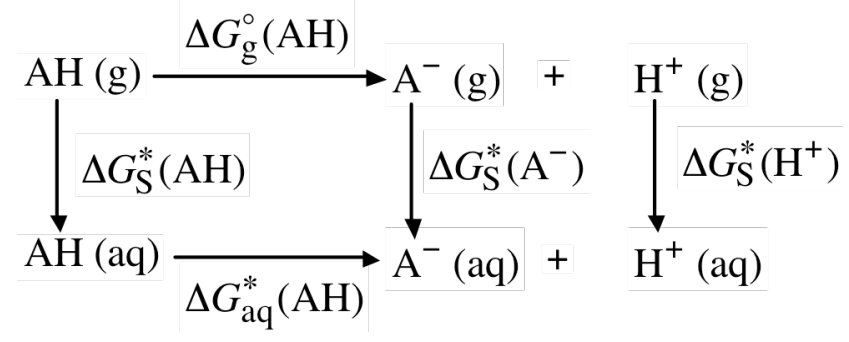

Scheme 2: Thermochemical Cycle 2

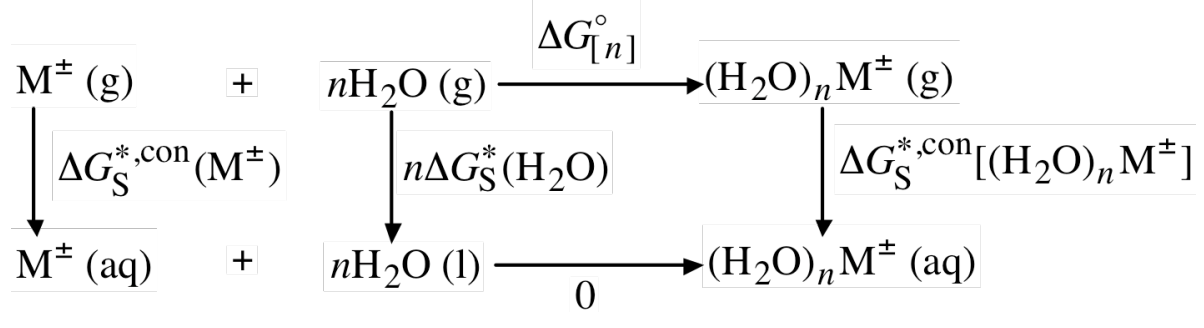

Scheme 3: Thermochemical Cycle 3 